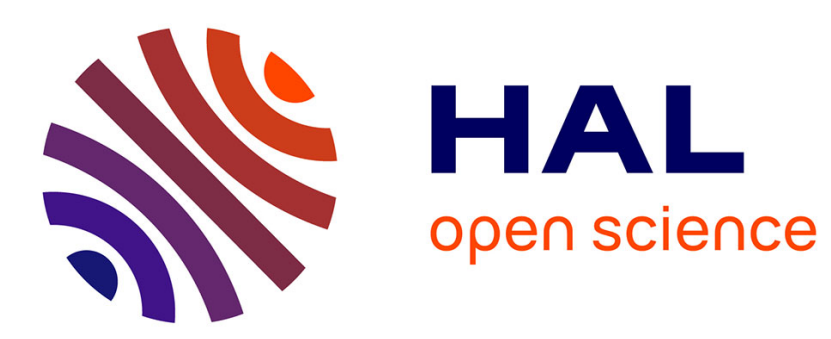

\title{
Stability and strength of male-female associations in a promiscuous primate society
}

Alice Baniel, Guy Cowlishaw, Elise Huchard

\section{To cite this version:}

Alice Baniel, Guy Cowlishaw, Elise Huchard. Stability and strength of male-female associations in a promiscuous primate society. Behavioral Ecology and Sociobiology, 2016, 70 (5), pp.761-775. 10.1007/s00265-016-2100-8 . hal-01950152

\section{HAL Id: hal-01950152 \\ https://hal.science/hal-01950152}

Submitted on 20 Dec 2018

HAL is a multi-disciplinary open access archive for the deposit and dissemination of scientific research documents, whether they are published or not. The documents may come from teaching and research institutions in France or abroad, or from public or private research centers.
L'archive ouverte pluridisciplinaire HAL, est destinée au dépôt et à la diffusion de documents scientifiques de niveau recherche, publiés ou non, émanant des établissements d'enseignement et de recherche français ou étrangers, des laboratoires publics ou privés. 
Published in final edited form as:

Behavioral ecology and sociobiology 70.5 (2016): 761-775. doi:10.1007/s00265-016-2100-8

Stability and strength of male-female associations in a

\author{
Alice Baniel $^{1,2,3,}$, Guy Cowlishaw $^{3}$, Elise Huchard ${ }^{1}$
}

\title{
AUTHORS AFFILIATIONS
}

${ }^{1}$ Centre d'Ecologie Fonctionnelle et Evolutive, Unité Mixte de Recherche 5175, Centre National de la Recherche Scientifique, 1919 Route de Mende, 34293 Montpellier Cedex 5,

France

${ }^{2}$ Institut des Sciences de 1'Evolution de Montpellier, Université de Montpellier, Place Eugène Bataillon, CC 065, 34095 Montpellier Cedex 5, France

${ }^{3}$ Institute of Zoology, The Zoological Society of London, Regent's Park, London NW1 4RY, UK

${ }^{\S}$ Corresponding author: Alice Baniel, Centre d'Ecologie Fonctionnelle et Evolutive, Unité Mixte de Recherche 5175, Centre National de la Recherche Scientifique, 1919 Route de Mende, 34293 Montpellier Cedex 5, France, telephone: +33467613247, fax: + 33467613336, email address: alice.baniel@gmail.com 


\section{ABSTRACT}

Close associations between adult males and lactating females occur in several promiscuous primate species. Benefits gained by males from such bonds may include increases in offspring fitness through paternal effort (the "mate-then-care" hypothesis) and/or subsequent mating opportunities with the female (the "care-then-mate" hypothesis). Heterosexual friendships between males and females have been described as tightly linked to the presence of a dependent infant, but few studies have investigated whether these associations may be longer, starting before an infant birth and lasting after its independence, and whether they may vary in strength across time and dyads. We investigated the stability and strength of heterosexual bonds in two groups of wild chacma baboons (Papio ursinus) to test whether male-female associations (1) last from offspring conception to independence, as expected under the matethen-care hypothesis, (2) last after maternal cycling resumption and increase male mating success, as expected under the care-then-mate hypothesis, and (3) vary in strength depending on female reproductive state, age and rank. Our results show that most male-female bonds are already present at offspring conception, are maintained during pregnancy and lactation, and disappeared when mother resumed cycling. Moreover, heterosexual bonds were most intense during early lactation and for high-ranking females, and did not predict subsequent mating activity. Those findings favour the mate-then-care hypothesis, and confirm that male paternity assessment may, at least partially, rely on mating history. Overall, stable heterosexual friendships exist outside early lactation and last longer than previously thought, suggesting that male-female bonds could play an important and under-appreciated role on the social structure of groups in promiscuous primate societies.

\section{SIGNIFICANCE STATEMENT}


Stable male-female bonds are rare in promiscuous mammals. Baboons are unusual in this respect: tight friendships have been described between adult males and lactating females and may protect infants against infanticide, but few studies have investigated whether these associations may start before an infant's birth, or extend after its nutritional independence. We explored the stability and strength of heterosexual relationships in the chacma baboon, and found that friendships start before infant's conception, are maintained throughout pregnancy, strengthen during lactation and disappear before mothers resume cycling. Such pattern of association suggests that male-female bonds represent paternal effort, and may arise from sexual activity before and during the conceptive cycle. Most females appear permanently associated with one male regardless of their reproductive state, suggesting that heterosexual bonds play an important, and under-appreciated, role in structuring the social organization of baboon societies.

KEYWORDS: friendship, male-female association, paternal care, mating success, chacma baboon, Papio ursinus

\section{ACKNOWLEDGMENTS}

We are thankful to the Tsaobis Baboon Project volunteers in 2013 and 2014 for invaluable help in the field, in particular to Ignacio Abadia Suanzes-Carpegna, Andrew Allan, Einat BarZiv, Katie Hatton, Caitlin Miller, Frieda Shikongo, Chris Smith and Agata Staniewicz. Our thanks also go to Alecia J. Carter, Alexander Lee and Cassandra Raby for running the field site in collaboration and for helpful discussions. We are very grateful to Alexandre Courtiol who wrote the mantel test script, as well as to Christof Neumann, Anja Widdig and one anonymous reviewer for their constructive comments on an earlier version of the manuscript. Permission to work at Tsaobis Nature Park is kindly granted by the Ministry of Lands and Resettlement, thanks to the Gobabeb Research and Training Centre for affiliation, and the 
72 Ministry of Environment and Tourism. We are also grateful to the Snyman and Wittreich

73 families for permission to work on their land, and to Herman Strydom and Willem Odendaal

74 for help in the field. This paper is a publication of the ZSL Institute of Zoology's Tsaobis 75 Baboon Project. Contribution ISEM 2016-050.

76 


\section{INTRODUCTION}

In group-living mammals, the quality and stability of social relationships can have important fitness consequences (Silk 2007a, b). In particular, social bonding and integration are known to influence fecundity and offspring survival (yellow baboons, Papio cynocephalus: Silk et al. 2003; chacma baboons, Papio ursinus: Silk et al. 2009; feral horses, Equus ferus caballus: Cameron et al. 2009; bottlenose dolphins, Tursiops sp.: Frere et al. 2010) as well as longevity (chacma baboons: Silk et al. 2010a, Archie et al. 2014; bottlenose dolphins: Stanton and Mann 2012). In humans (Homo sapiens) also, social integration can influence psychological stress (DeVries et al. 2003; Rosal et al. 2004), health (Cacioppo and Hawkley 2003; Uchino 2006) and survival (review in Holt-Lunstad et al. 2010).

Most studies have focused on the stability and benefits of same-sex relationships (Machanda et al. 2013; Archie et al. 2014), especially among members of the philopatric sex - namely females in most mammals (Handley and Perrin 2007) - who are more likely to maintain stable bonds because they co-reside for long periods with relatives (van Schaik 1989; Sterck et al. 1997). However, several studies have now reported that social relationships between males and females can also have important fitness consequences for both sexes, with benefits for offspring survival (savanna baboons: Palombit 2003), female longevity (chacma baboons: Cheney et al. 2012; Archie et al. 2014) and male mating or reproductive success (rhesus macaques, Macaca mulatta: Kulik et al. 2011; Massen et al. 2012; Assamese macaques, Macaca assamensis: Ostner et al. 2013).

Heterosexual bonds may be particularly important in primates. First, many primates form stable groups where males and females live together year-round, in contrast to other mammals where stable male-female associations are less common (van Schaik and Kappeler 1997). Second, in several polygynous primates, lactating females form preferential associations with particular males, often called "friendships" (olive baboons, Papio anubis: 
Smuts 1985; Lemasson et al. 2008; yellow baboons: Altmann 1980; Nguyen et al. 2009; chacma baboons: Palombit et al. 1997; Huchard et al. 2010; Moscovice et al. 2010; rhesus macaques: Manson 1994; Barbary macaques, Macaca sylvanus: Paul et al. 1996; Ménard et al. 2001). These relationships are characterized by a high level of spatial proximity and grooming interactions between partners and are actively maintained by females (Palombit et al. 1997; Huchard et al. 2010). Their benefits to females are thought to be mainly related to infanticide avoidance, where males protect vulnerable offspring (Palombit et al. 1997; Palombit 1999; Palombit 2000; Weingrill 2000), although further benefits may include protection from non-lethal conspecific aggression (Smuts 1985; Manson 1994; Lemasson et al. 2008; Nguyen et al. 2009; Kulik et al. 2012), reduced predation risk (van Schaik and van Noordwijk 1989), stress alleviation during social instability (Beehner et al. 2005; Engh et al. 2006) and promotion of male-infant associations after weaning, which can provide juveniles with support in agonistic interactions with conspecifics (Buchan et al. 2003) and foraging benefits (Charpentier et al. 2008; Huchard et al. 2013).

The benefits gained by males from such associations are less clear (Palombit 2000). There are two alternative, non-exclusive hypotheses. First, the "care-then-mate" hypothesis posits that males may trade protection services for reproductive opportunities (Seyfarth 1978a; Smuts 1985; review in van Schaik and Paul 1996), such that friendships increase a male's future chances of mating with his female friend. This hypothesis has received some support in olive baboons (Smuts 1985; Smuts and Gubernick 1992) and in Barbary macaques (Ménard et al. 2001), where friendships predicted mating frequency during following cycles. However, a relationship between male care-giving and subsequent mating activity has not been observed in other species (yellow baboons: Nguyen et al. 2009; chacma baboons: Weingrill 2000). Second, the "mate-then-care" hypothesis (Bales 1980; Smuts 1985; Moscovice et al. 2010) proposes that males form friendships based on their likelihood of 
paternity, in order to protect their own reproductive investment, i.e. to protect their offspring from infanticide. This hypothesis has received greater support. Several studies found that most males had mated with their female friend during her conceptive cycle (olive baboons: Smuts 1985; yellow baboons: Nguyen et al. 2009; chacma baboons: Palombit et al. 1997; Moscovice et al. 2010) and genetic studies confirmed that males are often - but not always the sire of the infant of their female friend (Moscovice et al. 2009; Nguyen et al. 2009; Huchard et al. 2010; Ostner et al. 2013).

These observations raise an important question, namely how males may assess their paternity in a promiscuous mating system. First, males might compare the phenotype of the infant to their own using facial, vocal or olfactory cues (phenotype matching, review in Widdig 2007). Alternatively, males might rely on their past mating history with the mother of the infant (Palombit et al. 1997; Moscovice et al. 2010). As male-female friendships are described to start with the birth of an infant (Palombit et al. 1997; Palombit 1999), such assessment of paternity may require complex cognitive abilities: males may have to identify which oestrus cycle corresponded to the conceptive cycle for a given infant, as well as to evaluate and remember his mating activity with the mother during that cycle, including the length of his monopolization (or the number of matings) in relation to the proximity of ovulation and the mating activity of rivals. A more parsimonious scenario is that male-female associations may not start with an infant birth but with its conception, and be subsequently maintained throughout pregnancy, though perhaps at lower intensity than following the birth because pregnant females do not face any risk of infanticide (but may still face a risk of socially-induced abortion, Alberts et al. 1992; Roberts et al. 2012). Male-female associations during pregnancy have been documented in Assamese macaques (Ostner et al. 2013) and in some baboon populations (olive baboons: Smuts 1985; chacma baboons: Weingrill 2000), but not in others (Palombit et al. 1997). It may therefore be necessary to assess the stability of 
heterosexual relationships over longer periods, namely from infant conception to independence and beyond, as well as how their strength may vary across such periods, to better understand the function of heterosexual relationships, and the mechanisms favouring their formation.

Here, we analyse the stability and strength of male-female associations in wild chacma baboons. Chacma baboons live in large multimale multifemale societies where females are philopatric and establish stable, linear and heritable dominance hierarchies, in which daughters rank below their mother (Seyfarth 1976; Bergman et al. 2003). As in most baboon societies, male chacma baboons compete to access dominance, which rules access to mating opportunities (Bulger 1993; Weingrill et al. 2003). High-ranking males mate guard oestrous females by forming 'consortships' during which they maintain close spatial proximity and monopolize sexual access at the most likely time of ovulation (Bulger 1993; Weingrill et al. 2003). Infanticide risk is high in chacma baboons, which may, in turn, promote the formation of heterosexual associations in the first year of infant life, when its vulnerability is high (Palombit 2003). Lactating females are primarily responsible for the maintenance of such social bonds (Palombit et al. 1997; Huchard et al. 2010) and compete over access to male partners, as higher-ranking females form stronger bonds with the dominant male (Seyfarth 1978) and high-ranking mothers actively prevent lower-ranking mothers from gaining access to their male friends (Palombit et al. 2001).

This study has three objectives. First, we assess the stability of male-female bonds across female reproductive states to test whether male-female relationships last from offspring birth to the resumption of maternal cycling and/or to next conception, as predicted by the care-then-mate hypothesis, or alternatively from offspring conception to independence, as predicted by the mate-then-care hypothesis. Second, we assess whether females or males are primarily responsible for the maintenance of close proximity between friends throughout 
177 female reproductive states. We expected males to be responsible for proximity maintenance when females were sexually receptive and then a role reversal, with females maintaining proximity during pregnancy and lactation, as females may get more benefits than males from these associations during these stages. Third, we examine how the strength of spatial associations between males and females varies across the successive reproductive states of a female. We predict that heterosexual bonds would be the tightest during early lactation (0-6 months) when the infant is presumably at the highest risk of infanticide (Palombit et al. 2000; Palombit 2003), would weaken or stop as the infant becomes less vulnerable to infanticide (>6 months and until weaning), and would be weak during pregnancy when there is no risk of infanticide. The strength of heterosexual associations may however also vary across dyads, based on male and female rank. If females compete over male proximity, higher-ranking females may maintain more stable bonds, while higher-ranking males who are most successful at monopolizing females may have higher paternity certainty and display stronger associations with females subsequently.

\section{Materials \& Methods}

\section{Field site and study subjects}

We studied a population of wild chacma baboons living at Tsaobis Nature Park, on the edge of the Namib desert, Namibia $\left(22^{\circ} 22^{\prime} \mathrm{S} 15^{\circ} 44^{\prime} \mathrm{E}\right)$ (for detailed information on the field site and population, see Cowlishaw 1997). Data were collected in June-October 2013 and MayNovember 2014 on two large groups of baboons: J group (2013: 7-10 males, 17 females, 2932 juveniles; 2014: 7-8 males, 18 females, 35 juveniles) and L group (2013: 9-11 males, 1819 females, 31-33 juveniles; 2014: 9 males, 17-19 females, 29 juveniles). All adults were individually recognizable and fully habituated to observation at close range. Age (in years) was estimated from a combination of known birth dates and dental patterns of tooth eruption 
and wear, examined during prior captures (Huchard et al. 2009). Only adults were included in the study. Males were considered adult when they reached eight years of age (Alberts and Altmann 1995) and females when they reached menarche (Altmann and Alberts 2003). Female parity (nulliparous, primiparous, multiparous) was taken from life-history data.

The reproductive state of each female was monitored on a daily basis and categorized according to a chronology followed from the last cycle before birth (the conceptive cycle) to the first cycle after birth. First, we considered the "swollen" period of the conceptive cycle during which females were sexually receptive with a perineal swelling ("SWc"). Conceptive cycles were distinguished from non-conceptive cycles a posteriori, identified as the last cycle preceding pregnancy. To test the care-then-mate hypothesis, we further included all documented swollen periods of a particular interbirth interval. Pregnancy ("P") was determined a posteriori and encompassed the six months separating the conceptive cycle from an infant birth. Lactation referred to the entire period during which females had a dependent infant and were not cycling and was split between the first six months of lactation ("L1") and the rest of lactation ("L2"). Finally, "SW1" refers to the first swollen period after lactational amenorrhea when females resume cycling.

\section{Behavioural observations}

Observers on foot followed both groups daily from dawn to dusk, conducting focal animal sampling (Altmann 1974) on all adult males and females. All observers (except AB) were blind with respect to the research questions. Focal follows lasted 60 minutes on average (mean focal length \pm sd: $58.6 \pm 7.2 \mathrm{~min}$, range: $23-97 \mathrm{~min}$ ) and were spread equally across the day (split into four three-hour time blocks) for each individual. The focal individual was chosen in a semi-random manner, in order to balance observation time equally across individuals, and, for females, across reproductive states, and was only sampled once per day. 
A total of 903 focal observations of 75 females were included in the analysis (here the statistical unit 'female' is a female in a particular reproductive state) distributed across the following reproductive states: pregnant $(\mathrm{N}=496$ observations of 37 females, range: 4-23, mean \pm sd: $13.4 \pm 4.8$ ), early lactating $(\mathrm{N}=239$ observations of 20 females, range: 5-18, mean \pm sd: $12.0 \pm 4.3)$ and late lactating $(\mathrm{N}=168$ observations of 18 females, range: 4-15, mean \pm sd: $9.3 \pm 3.3$ ). A total of 538 focal observations of 24 males were collected (number of observations per male: range: $10-37$, mean \pm sd: $22.4 \pm 8.6$ ). During focal observations, we continuously recorded all agonistic interactions (supplants, displacements, attacks, threats, see Huchard and Cowlishaw (2011) for definitions), and social and sexual interactions (including grooming bouts and copulations), along with the identity of the other individuals involved and the direction of the interaction. We also noted all approaches and leaves between adult males and females within 1 meter. During female focal follows, we also recorded proximity scans every five minutes to note the identity and distance of the nearest male neighbour.

In addition, throughout the day, we collected ad libitum agonistic interactions and grooming bouts, again with the identity of individuals involved. Observers moved regularly through the group to look for focal individuals which ensured that the ad lib grooming data provided an unbiased representation of overall grooming interactions. Consortships were defined as periods when swollen females were constantly followed by a male who mated exclusively with them (Alberts et al. 1996). Presence and changes in consortships were monitored ad lib on a daily basis.

Adult ranks were established using both ad lib and focal observations of agonistic interactions with the Elo-rating procedure (Albers and de Vries 2001) implemented in the R package EloRating (version 0.43) (Neumann et al. 2011). We computed separate female and male hierarchies and obtained a score for each individual for each day of observation. To obtain comparable ratings across the study period, we derived a daily standardized rank by 
scaling the Elo-rating score of each individual proportionally between 0 (corresponding to the minimal score and thus the lowest ranking individual) and 1 (corresponding to the maximal score and the highest ranking individual).

During the study period, the rate of alpha male takeover and male immigration were high in both groups ( 1 and 4 immigration events in J group in 2013 and 2014 respectively; 6 and 1 immigration events in L group in 2013 and 2014 respectively), leading to some unstability into male dominance hierarchies (see Fig. S1-S4 in Online ressource). Concerning J group, dominance hierarchy was stable in 2013 with the same alpha male for the entire study period (Fig. S1), while 2014 was very unstable with five males competing constantly for dominance and alternating in reaching the alpha male status (Fig. S2). Concerning L group, in 2013 the alphamale lost his dominance in July 2013, then another resident male reached alpha status but concomitently two new males immigrated and rised in rank, causing high instability in the hierarchy (Fig. S3). In 2014, the dominance was contested among three males who alternated as alpha males, then one new male immigrated toward the end of the study period and reached dominance (Fig. S4).

\section{Data analysis}

\section{Stability of male-female associations across reproductive states}

We assessed the stability of male-female preferential associations across the consecutive reproductive states of each female, in order to test (1) whether females remain associated to the most likely father of their offspring from its conception to its independence (as predicted by the mate-then-care hypothesis), or alternatively, (2) whether male-female relationships predict the male's chances of subsequently consorting with her and/or increase his likelihood of siring her next offspring (as predicted by the care-then-mate hypothesis). 


\section{Identification of the most likely father}

Following previous studies (Smuts 1985; Nguyen et al. 2009; Moscovice et al. 2010), we defined the most likely father of an infant as the male who mate-guarded the female during the fertile period of her conceptive cycle, defined as the five days preceding the day of detumescence when the probability of ovulation is maximal (Higham et al. 2008; Daspre et al. 2009). On 56 fully observed cycles, sexual receptivity lasted $22.1 \pm 5.5$ days (mean \pm sd) on average (range: 13-43) and the number of consort males per swollen cycle was $1.1 \pm 0.6$ (mean \pm sd) (range: $0-2)$. Consortships lasted 8.8 \pm 6.0 days (mean \pm sd) on average (range: 0.532, $\mathrm{N}=48$ cycles). On 74 cycles observed during the fertile period (i.e. 5 days before detumescence), the number of consort males during the fertile period was $0.99 \pm 0.6$ (mean \pm sd) (range: 0-2) and consortships during the fertile period lasted 3.9 \pm 1.5 days (mean \pm sd) (range: 0.5-5, $\mathrm{N}=60$ cycles). As a result, only one male monopolized the female during the fertile cycle in most cycles and assignments of most likely father were straightforward. On 3/26 conceptive cycles, two males consorted with a female consecutively during the fertile period. However, the time spent in consortship was always very biased toward one male (mean percentage of monopolization by the main male \pm sd: $83 \% \pm 11 \%$ ) so we selected that male as the most likely father.

\section{Identification of the male friend}

During pregnancy, early lactation and late lactation, we identified the male friend of each female from the dyadic proximity and grooming scores with all males in the group, as follows.

Grooming. A grooming allocation index quantified grooming given by females to males and relied on a combination of $a d$ lib and male and female focal observations (see Table S1 in the Online Resource for sample sizes). Grooming bouts involving the same dyad 
were discarded if they occurred within 30 minutes of a previous bout, in order to ensure independency among bouts. The strength of connection of a male-female dyad was estimated as the share of grooming that a female allocated to a particular male, calculated as the number of grooming bouts that a female gives to a male divided by the total number of grooming bouts given by that female to any male during the period when this male was resident in the group. This index controls for variation across females in the total time spent socializing with males, as well as for variation across males in the time spent in the group.

Spatial proximity. A spatial proximity index was calculated using female focal observations only (see Table S1 in the Online Resource for sample sizes). Every five minutes, scans recorded the identity and distance of the nearest adult male. The strength of connection of a male-female dyad was calculated as the number of scans where the male was the female's nearest neighbour divided by the total number of informative scans (i.e., for which the nearest neighbour is identified) collected for that female over the time period during which the male was resident in the group. In a few scans $(0.3 \%)$, two adult males were equally distant. These scans were counted in the dyadic index of both males. At Tsaobis, visibility is most of the time excellent, and facilitates the collection of accurate proximity data. Male nearest neighbours were on average at 14.0 \pm 13.9 meters (mean \pm sd, range: $0-150 \mathrm{~m}$ ) from females. The mean percentage $( \pm \mathrm{sd})$ of informative scans per focal observation was $71.8 \%( \pm 8.7 \%)$. Other, non-informative scans were omitted by observers, or impossible to collect because of poor visibility conditions, or because the focal individual was isolated from the rest of the group.

For both indices, we favoured the use of relative over absolute measures of heterosexual associations (i.e., we calculated female allocation of grooming and proximity toward each male, rather than absolute frequency of grooming or time spent in proximity of each male) in order to identify the favourite male(s) social partner of females while 
controlling for differences in sociality among females (some females may be more social than others). We assessed the significance of the Pearson correlation between grooming and proximity indices of all heterosexual dyads using a Mantel test and 1000 permutations. The test compares the observed Pearson correlation between the matrices of proximity and grooming to the simulated correlation (where dyadic values are randomized 1000 times within a female).

For each behavioural index, we investigated if one or two males had an outstandingly high score compared to other males, hereafter referred as the "preferred male(s)". We ranked males from the highest to the lowest score, then calculated the ratio of the highest index divided by the second highest index and the ratio of the second highest index divided by the third highest index. If the first ratio was higher than two (i.e. the male with the highest index had twice as many interactions with the female than the second male), we assigned only one preferred male - the one with the highest score - to the female. If the second ratio was also higher than two, we assigned two preferred males - the ones with first and second highest indices - to the female. Otherwise, we considered that the female had no preferred male for this reproductive state. Thus, females could have one, two or no preferred male(s) if no male had a highly differentiated score compared to the others. Then, we compared the preferred male(s) designated by each behavioural index and considered as "male friend" the male that was preferred according to both grooming and proximity indices (see Supplementary text in the Online Resource for more details regarding male friend attribution, including cases of discrepancy between the preferred male(s) assigned by each index). Several females had more than one offspring during the study period and observations of the same female in a different interbirth interval were considered separately, as the male associate may likely change in different interbirth intervals. 
$\underline{\text { Test of the stability of male-female association between consecutive reproductive states }}$

Test of the mate-then-care hypothesis. We assessed whether females remain associated with the most likely father of their offspring from conception to pregnancy (SWc-P) and with the same male friend from pregnancy to lactation (P-L) of the same interbirth interval. For the latter, we pooled females in both early and late lactation due to sample size limitation. We tested whether the identity of the most likely father/male friend remained consistent in the second state relative to the first state using two-tailed permutation tests. We only included cases where the most likely father/male friend of the first reproductive state was still in the group during the second reproductive state of the female. For each female, we created a pool of males that were present in the two reproductive states of interest and assigned 1 to the most likely father/male friend of each state. We randomized 50,000 times the identities of the most likely father/male friend in one state, computed the random distribution of the proportion of females associated with the same male across both reproductive states, and compared it to the observed proportion (i.e. based on the original data). The exact two-tailed p-value was computed as the proportion of cases displaying a higher or lower value than the observed correlation on the upper or lower tail of the simulated distribution, respectively.

Test of the care-then-mate hypothesis. We used two complementary approaches. First, we tested whether friendships predict male consortships during any future cycle of the next interbirth interval. We used all cycles for which the identity of the previous male friend was known, and for which he was still present in the group. For each cycle of each female and for each male, we recorded whether he mate-guarded the female or not (regardless of whether it was during the fertile period), and analysed variation in this variable using a generalized linear mixed-effect model with a binomial error structure and logit link function. Fixed effects included a categorical variable "Previous friend? (yes/no)", male rank (averaged across the 
period considered) and group membership. Random factors included the identity of the cycle, female and male.

For all mixed models in our study, the statistical significance of the full model was assessed by comparing its fit with the respective null model (containing only the random factors) using a log-likelihood ratio test (LRT). Given the significance of the full model, the significance of the fixed factors was tested using a LRT test (assuming an asymptotic chisquare distribution of the test statistic), and using the full model (to avoid problems arising from stepwise model selection procedures: Whittingham et al. 2006; Mundry and Nunn 2009). We further computed the $95 \%$ confidence intervals (using the confint.merMod function) of fixed factors (for multilevel categorical variables, confidence intervals were used to test the significance of each level of the variable by checking that they did not cross zero). To test for all differences between levels of a multilevel categorical variable, we changed the reference category sequentially (Pinheiro and Bates 2000). Model stability was assessed by randomly splitting the dataset in two and running the same GLMMs on the two subsets in order to check the robustness of estimates and significance of fixed effects (results not shown). All GLMMs were run using the lme4 package (Bates et al. 2014) in R version 1.1-7 (R Core development Team 2015).

Second, we restricted the previous dataset to conceptive cycles only, to test whether male friends were the most likely fathers of their next offspring. We only included cases where the previous friend was still in the group after the female had resumed cycling. Here, there was only one cycle per female and a limited sample size, so that the significance of the stability of male-female associations across reproductive states (Previous friend-SWc) was assessed using two-tailed permutation tests as detailed above, rather than GLMMs.

\section{Maintenance of proximity with male friend across female reproductive states}


We subsequently investigated, for each male-female association in each reproductive state (i.e., between each female and her consort during periods of sexual receptivity, and between each female and her male friend during pregnancy, early lactation and late lactation), who was primarily responsible for maintaining spatial proximity (within $1 \mathrm{~m}$ ) and whether their roles changed according to female reproductive state. Using focal observations from both females and males, we extracted the number of approaches and leaves within $1 \mathrm{~m}$ that were initiated by the male associate (consort or friend) or by the female and computed a 'Hinde's index' for each dyad, calculated as the percentage of approaches minus the percentage of leaves initiated by the female and directed toward her male associate (Hinde and Atkinson 1970; Hinde and Proctor 1977). The Hinde's index ranges from -100 (male is totally responsible for maintaining proximity) to +100 (female is totally responsible for maintaining proximity), and was calculated only for dyads for which a minimum of 20 approach-leave interactions were available in a given reproductive state of the female (mean \pm sd:61.7 \pm 38.2 interactions per dyad, range: $21-199, \mathrm{~N}=60$ dyads). We tested whether the average of Hinde's index values for a particular reproductive state differed from zero using a one sample t-test.

\section{Strength of heterosexual associations depending on female reproductive state}

We finally investigated variation in the strength of male-female preferential associations in relation to changes of reproductive state. We ran two mixed-effect models which aimed at investigating variation in the frequency of association (1) between a female and the most likely father of her offspring (i.e. her consort during the conceptive cycle) and (2) between a female and her male friend. The response variables of the models were binary and recorded, for each scan of a female focal observation, whether or not the nearest male neighbour was (1) the likely father or (2) the male friend. Models were run with a binomial error structure and logit link function. In both models, the fixed effects included female 
reproductive state, female dominance rank, female parity, male dominance rank, group identity and year. Random effects included female identity, male identity and focal follow. In the first model, we were interested in measuring variation in the strength of male-female associations from conception, so the different levels of our variable "reproductive state" included the swollen period of the conceptive cycle (including periods outside consortship), pregnancy, early and late lactation. In contrast, in the second model, the male friend of a female was not always the same across her successive reproductive state but we measured variation in association with the male designated as her friend for any particular reproductive state. These models were run as described above.

\section{RESULTS}

\section{Stability of male-female associations across reproductive state}

\section{$\underline{\text { Identification of the behavioural male friend }}$}

The distribution of grooming and proximity indices among males, when ranked from the highest to the fifth highest score, revealed that the strongest gap lies between the first and second male within each index, while differences among subsequent males are considerably weaker (Fig. 1a). This indicates that most pregnant and lactating females have a particularly strong relationship with one male. One or two preferred male(s) were assigned to $96 \%$ of females with the grooming index, and one or two male(s) were assigned to $61 \%$ of females with the proximity index (see Table S2 in the Online Resource); other females did not have any preferred male. Grooming and proximity indices were highly positively correlated across dyads (Mantel test with Pearson correlation: $\mathrm{r}=0.83, \mathrm{~N}=67$ females, $\mathrm{p}=0.001$ ). As a result, both indices were very congruent and assigned the same male in 97\% of cases (see Online Resources for more details). After the consensus between the two indices, all females had only one male friend (i.e. there was no case where the same two males were considered as 
preferred by both indices). Overall, we defined one male friend for $83 \%$ of females ( $N=67$ out of 81 ), including $83 \%$ of pregnant females, $95 \%$ of females in early lactation and $68 \%$ of females in late lactation. Male friends obtain a much higher share of grooming and proximity than non-friend males (Fig. 1b). In total, $70 \%$ of females and $55 \%$ of males were involved in at least one friendship during the study period.

\section{$\underline{\text { Test of the mate-then-care hypothesis }}$}

In support of the mate-then-care hypothesis, females remained associated with the same male from offspring conception to independence (Table 1). The highest stability in association patterns occurred between the swollen period of the conceptive cycle and pregnancy (SWc-P), as 21 out of 25 females kept the same male associate. Ten of 19 females were also associated with the same male from pregnancy to lactation (P-L). Notably, of the nine cases where females were not associated with the same male in pregnancy and lactation, six had no male friend during pregnancy and only started to associate with a male during lactation. Six females out of 44 properly switched their male associate from conception to pregnancy (SWc$\mathrm{P}$ ) or from pregnancy to lactation (P-L). For five out of those six females, the male associate of the first reproductive state was always in the top two highest scores of grooming and/or proximity index during the second state, suggesting that females may still maintain a bond with the likely father of their offspring, even when they mainly associate with another male. Overall, those results suggest that most male-female associations are stable from infant conception to weaning.

\section{$\underline{\text { Test of the care-then-mate hypothesis }}$}

When integrating information on all cycles for which the identity of the female's friend during her previous interbirth interval was known, females were seen in consortship with their 
previous male friend in six out of 20 cycles. The GLMM predicting the probability of consorting between a male and a female as a function of their previous friendship (yes/no) and of male rank was not significant (log-likelihood ratio test comparing the fit of the full model with a null model containing only the random effects; $\chi^{2}=4.4, \mathrm{df}=3, \mathrm{~N}=20$ cycles, $\mathrm{p}=0.222$ ), suggesting that prior friendship does not predict a male's likelihood of mate-guarding a female when she resumes cycling. When restricting the analysis to conceptive cycles, we similarly found that friendship during pregnancy and lactation did not increase male chance of consorting with a female during the fertile period of her next conceptive cycle (Table 1). Out of 10 females for which information on the identity of her previous friend and next consort was available, only one consorted with her previous friend.

\section{Sex roles in the maintenance of proximity across female reproductive states}

Average Hinde's indices were negatively and significantly different from zero for the swollen period of the conceptive cycle (one sample t-test, $\mathrm{N}=19, \mathrm{t}=-6.7, \mathrm{p}<0.001$ ) and for pregnancy (one sample t-test, $\mathrm{N}=20, \mathrm{t}=-5.7, \mathrm{p}<0.001$ ) (Fig. 2), meaning that males were primarily responsible for maintaining close proximity with their female associate during these periods. Pregnancy becomes conspicuous approximately 3-4 weeks after conception in baboons, when females exhibit a reddening of the paracallosal skin, called 'pregnancy sign' (Gilbert and Gillman 1952; Altmann 1973). In an attempt to understand whether males may keep maintaining proximity during pregnancy simply because they fail to detect early pregnancies, we calculated Hinde's indices between females and their consort partner when they are cycling but not swollen (i.e. when the previous oestrus cycle did not lead to conception), during their first month of pregnancy (when pregnancy is inconspicuous) and maintained close proximity to cycling females (one sample t-test, $\mathrm{n}=16, \mathrm{t}=-5.1, \mathrm{p}<0.001$ ), 
501 females in early pregnancy (one sample t-test, $\mathrm{n}=8, \mathrm{t}=-6.7, \mathrm{p}<0.001$ ), and also to a lesser

502

503

504

505

506

507

508

509

510

511

512

513

514

extent to females that were at a later stage of pregnancy (one sample t-test, $\mathrm{n}=8, \mathrm{t}=-2.6$, $\mathrm{p}=0.033$ ). Thus, males remained primarily responsible for maintaining proximity throughout pregnancy (Fig. S5). By contrast, the average Hinde's indices were positive and significantly different from zero during early lactation (one sample t-test, $\mathrm{N}=17, \mathrm{t}=2.8, \mathrm{p}=0.014$ ), indicating that females were responsible for close proximity maintenance, while both males and females were equally responsible for maintaining contact during late lactation (one sample t-test, $\mathrm{N}=4, \mathrm{t}=-1.4, \mathrm{p}=0.266)$ (Fig. 2).

\section{Strength of heterosexual associations depending on female reproductive state}

$\underline{\text { Variation in the strength of association between females and the most likely father }}$

The strength of association between females and their male friend was estimated by the probability of spatial proximity between partners in any given scan. The set of predictor variables used had a clear influence on the probability of association between females and the likely father of their current offspring (log-likelihood ratio test comparing the fit of the full model with a null model containing only random effects; $\left.\chi^{2}=64.2, \mathrm{df}=9, \mathrm{p}<0.001\right)$. The probability of association between females and the most likely father of their offspring varies according to female reproductive state (Fig. 3a). Namely, the probability of association is highest during the swollen period of the conceptive cycle and early lactation, and lowest during pregnancy (Table 2a, Fig. 3a). In addition, high-ranking females had a higher probability of association with the likely father compared to low-ranking females. Similarly, higher-ranking males exhibited a higher probability of association with females. Finally, female parity was also important, with multiparous females being most often associated with the likely father. 
Variation in the strength of associations between females and their male friend

The set of predictor variables used influenced the probability of association between females and their male friend (log-likelihood ratio test comparing the fit of the full model with a null model containing only random effects; $\left.\chi^{2}=54.8, \mathrm{df}=9, \mathrm{p}<0.001\right)$. The probability of association between a female and her male friend varied according to female reproductive state (Fig. 3b). The probability of association increased from pregnancy to early lactation, decreased from early to late lactation and decreased again from late lactation to the first postpartum swelling, where association with the male friend of the previous interbirth interval was weakest (Table 2b, Fig. 3b). Beyond reproductive state, female rank also had an effect on the probability of association, with high ranking females being more likely to be associated with their male friend.

\section{DISCUSSION}

This study investigated the structure and stability of heterosexual bonds in chacma baboons. While previous studies have emphasized the occurrence of strong bonds between lactating females and an adult male shortly after the birth of an infant, our results suggest that males and females form stable and preferential relationships at least from conception until the end of lactation. Here we explore the implications of our findings for our understanding of the function of heterosexual associations in baboons.

We found that $70 \%(\mathrm{~N}=31 / 44)$ of females have the same male friend over time, either from conception to pregnancy or from pregnancy to lactation, while 14\% ( $\mathrm{N}=6 / 44)$ switch their male friend in one or the other transition. The remaining 16\% (N=4/44) of females were not associated to any friend during one state (mainly during pregnancy). Thus, overall, most but not all - male-female bonds last from offspring conception to lactation. By contrast, friendships did not significantly increase a male's chance of siring the next offspring of his 
551 female friend, suggesting that in chacma baboons, heterosexual associations have not evolved

552 in response to mating benefits. Overall, our results indicate that friendships tend to follow,

553 rather than precede, sexual activity between friends which suggests that male involvement in

554 heterosexual friendships represents paternal care rather than mating effort. Although our study

555 assesses the correlation between friendships and the probability of paternity (inferred from

556 consortship activity during the conceptive cycle), rather than actual paternity, our results are

557 consistent with previous studies investigating the correlation between friendships and actual

558 paternity data in savanna baboons, showing that most male friends of lactating females had sired their friend's infant (Nguyen et al. 2009; Huchard et al. 2010; Moscovice et al. 2010). In addition, it's important to note that we attributed as male friend to a female the male who was both her most frequent male nearest neighbour and her main male grooming partner. These criteria are meant to maximize our ability to detect and characterize differentiated malefemale relationships, regardless of variation in the degree of sociality between females. However, they do not quantify the total amount of time that friends actually spend (or groom) together. This may represent another important axis of variation to consider when examining the functional consequences of heterosexual relationships, as it could be associated with differences in the expression of paternal behaviour.

Our finding that most male-female associations exist just after conception, and are maintained throughout pregnancy, suggests that males may assess their paternity using simple rules, such as protecting offspring born to the female(s) with whom they have become 571 associated after consorting with them during the conceptive cycle. In previous studies, the 572 observation that tight male-female associations only started during lactation (Palombit et al. 573 1997; Palombit 1999), six months after conception, raised the question of how males might assess their paternity. Several studies suggested that males may rely on their past mating history, as they were found to form friendships based on mating effort and particularly on the 
frequency and timing of copulations during the fertile period of a female's conceptive cycle (Palombit et al. 2000; Weingrill 2000; Moscovice et al. 2010). In Moscovice et al.'s study, females associated mainly with their main consort partner of the conceptive cycle and, when he was not present in the group around infant birth, they formed a friendship with their second former consort partner. This hypothesis suggests that males track and memorize their mating activity, and possibly that of their rivals, and eventually link the birth of the offspring to the conceptive cycle. Our results suggest an additional potential rule-of-thumb for male paternity assessment that relies on past mating history without requiring males to remember all their mates over the past 6-months period: male-female bonds may start during consortships and be subsequently maintained throughout pregnancy and lactation. It is important to note that males need to tolerate female friends selectively (and thus keep track of their previous mating activity) only if being involved in a friendship with a female is costly. If friendships are not costly to males, males may tolerate any female willing to associate with them and the observed pattern of male-female associations could be driven by a combination of female choice to associate with a male that does not represent a threat of infanticide given their mating history, and of male tolerance for any female.

At the proximate level, the formation and maintenance of affiliative pair-bonds and social relationships between mates have been show to be facilitated by physiological changes in oxytocin levels of females in monogamous rodents (Witt et al. 1990; Williams et al. 1994; Cushing and Carter 2000), non-human primates (Smith et al. 2010; Snowdon et al. 2010) and humans (Grewen et al. 2005; Feldman et al. 2012). Interestingly, in chacma baboons, females experience a surge of oxytocin during the period of most likely ovulation, and mate-guarded females displaying higher levels of oxytocin were found to maintain closer proximity to their consort partner (Moscovice and Ziegler 2012). Together with the present result that malefemale associations exist from the conceptive cycle, this suggests that the formation of 
heterosexual bonds in baboons might be hormonally mediated during consortships and subsequently maintained until infant's independence.

Preferential male-female bonds during pregnancy have already been documented in some baboon populations (Smuts 1985; Weingrill 2000, this study, but see Palombit et al. 1997) but have rarely been investigated otherwise. In our population, 83\% of pregnant females had a male friend. It is possible that looser bonds during pregnancy and late lactation may have led observers to focus on the stronger associations observed during early lactation (Palombit et al. 1997; Lemasson et al. 2008; Huchard et al. 2010; Moscovice et al. 2010). Male-female associations during pregnancy could have several benefits to both partners. In group-living species, foetus survival depends on a range of social and ecological variables and may impact the fitness of partners of both sexes (Kerhoas et al. 2014). Friendships with males during pregnancy could decrease risks of miscarriage if males support their female friend in conflicts with conspecifics (Seyfarth 1978; Smuts 1985), improve her feeding success by sharing foraging patches (King et al. 2008; Kaplan et al. 2011), or more generally contribute to decrease her physiological stress level (Smuts 1985; Weingrill 2000). In the latter case, several studies have reported an increase in abortion rates following male immigration into social groups ("Bruce effect", e.g. geladas, Theropithecus gelada: Roberts et al. 2012; yellow baboons: Pereira 1983; Alberts et al. 1992; hamadryas baboons, P. hamadryas: Colmenares and Gomendio 1988; Hanuman langurs, Presbytis entellus: Agoramoorthy et al. 1988). Other studies have shown that lactating females with male friends experienced smaller increases in stress levels (than those without friends) when a new male immigrated (Beehner et al. 2005; Engh et al. 2006), and it is possible that pregnant females would experience the same benefits. From a male perspective, associating to the pregnant female who carries his foetus may contribute to protect his reproductive investment and prevent foetal losses due to "Bruce effect". 
Responsibility for the maintenance of spatial proximity varies across the successive

627

628

629

630

631

632

633

634

635

636

637

638

639

640

641

642

643

644

645

646

647

reproductive states of a female. Females are responsible for maintaining proximity during early lactation, as found in other studies (Palombit et al. 1997, 2001; Huchard et al. 2010). However, the fact that males are primarily responsible for maintaining close proximity during pregnancy was unexpected, and may suggest that males benefit from these associations as much as, or more than, females. In addition to the reproductive benefits mentioned above, males associated with a familiar female may gain social benefits, by receiving more grooming and affiliation, which may alleviate stress levels (Aureli and Yates 2009; Ellis et al. 2011) or facilitate their social integration in a group (Smuts 1985). Alternatively, a cause for those results may be methodological. In this study, we assessed the maintenance of proximity within $1 \mathrm{~m}$. In contrast, previous studies used a composite proximity measure, called 'Cscore', which takes into account both close (0-1m) and intermediate (1-5m) proximity. Responsibility for the maintenance of close proximity (within 1m) mostly reflects the initiation of physical contacts between partners. As the direction of grooming is highly asymmetrical in heterosexual dyads (Palombit et al. 1997; Huchard et al. 2010), males may often approach females in a request to be groomed, and this may explain their responsibility in maintaining close proximity during pregnancy and the mixed maintenance during late lactation. A previous study assessing maintenance of close proximity (i.e. within $1 \mathrm{~m}$ ) between pregnant and lactating females and their male friend also found that males were responsible for proximity maintenance in over half of the dyads, while females where mostly responsible for maintaining proximity when using 0-5m proximity data (Smuts 1985). Analysing proximity data across the $0-5 \mathrm{~m}$ range is likely to provide a more accurate reflect of the overall maintenance of proximity among heterosexual partners.

Finally, we found important variation in the strength of friendships across female reproductive states. Friendships were most prevalent (involving 95\% of females) and most 
intense during early lactation, encompassing the first 6 months of an infant life, when the risk of infanticide is highest (Palombit et al. 2001; Palombit 2003). By contrast, only 68\% of females in late lactation were associated to a male friend and the strength of these associations decreased during this state compared to early lactation, suggesting that friendships might dissolve progressively, as infanticide risk decreases throughout infant development. The strength of friendships during pregnancy was lowest than during early lactation and comparable to late lactation. Evidence suggests that lactating females compete over male friends (Seyfarth 1978; Palombit et al. 2001). Pregnant females may renounce to stay around their friend at a time where the benefits of the association may not compensate the costs of competition.

In line with this, the strength of association with males was found to be influenced by female dominance rank, confirming that females were competing over access to male friends and their potential paternal services. In particular, high-ranking females, regardless of their reproductive state, associated more frequently to their male partner (friend and/or likely father of their offspring) than lower-ranking females. Female-female competition over males in chacma baboons was first reported in a two-male group where the dominant female seemed to prevent the formation of close bonds between the dominant male and other females (Seyfarth 1978). A subsequent study showed that high-ranking mothers maintained closer associations to their male friends and actively excluded lower-ranking mothers from male proximity where friendships overlapped (Palombit et al. 2001). A male's ability to protect infants might be limited by the number of females and/or infants associated with him at a given time (Palombit et al. 2001). For instance, high-ranking males Macaca nigra who are frequently mateguarding receptive females spend less time in proximity to their genetic offspring probably because they are seeking further mating opportunities instead of providing infant care (D. Kerhoas et al., unpubl. data). Similarly, subordinate male chacma baboons have fewer bonds 
with juveniles than dominant males, but maintain stronger bonds with their associated juveniles (Huchard et al. 2013).

A range of social and demographical parameters may influence the temporal stability of male-female bonds in chacma baboons. First, infanticide risk is known to vary both within and among populations (Palombit 2003) and is likely to affect the benefits of male-female bonds (Palombit 1999, 2012). In our case, several immigration events induced social instability in both groups during the course of this study, which may have raised female perception of infanticide risk, and their incentive to form friendships. Second, male breeding tenure may also be an important determinant of the stability of male-female bonds in large multimale groups. When male dominance hierarchy is stable over long periods of time, the same male-female bonds might continue after offspring independence and cover more than one interbirth interval. By contrast, if male dominance changes while a female is pregnant or in lactation, she might stop her association to conceive her next offspring with the new alpha male. In this study, male dominance changed in both groups between the two study periods, which may explain why most male-female bonds vanish after one interbirth interval.

To conclude, our findings suggest that heterosexual associations represent paternal effort rather than mating effort in chacma baboons, show greater temporal stability than previously thought, and vary in strength according to female reproductive state and dominance rank. We found that heterosexual friendships exist since infant conception, are maintained throughout pregnancy and strengthen at birth. Such pattern of association may clarify how males and females use their mating history to make decisions about heterosexual bonds by suggesting that long-term memory of prior mating activity is not necessary to invest into friendships and offspring care. In addition, our results indicate that most females are permanently associated with one male regardless of their reproductive status, suggesting that 
heterosexual bonds may play an important, and under-appreciated, role in the social organization and structure of baboon societies.

\section{COMPLIANCE WITH ETHICAL STANDARDS}

Funding: $\mathrm{AB}$ was supported by a studentship from the 'Ministère de l'Education Nationale, de l'Enseignement Supérieur et de la Recherche', France. Additional financial support was provided by a grant from the Primate Society of Great Britain.

Conflict of Interest: The authors declare that they have no conflict of interest.

Ethical approval: All applicable international, national, and/or institutional guidelines for the care and use of animals were followed. This article does not contain any studies with human participants performed by any of the authors.

\section{REFERENCES}

Agoramoorthy G, Mohnot SM, Sommer V, Srivastavz A (1988) Abortions in free ranging Hanuman langurs (Presbytis entellus) - a male induced strategy

Alberts SC, Altmann J (1995) Balancing costs and opportunities: dispersal in male baboons. Am Nat 145:279-306

Alberts SC, Altmann J, Wilson ML (1996) Mate guarding constrains foraging activity of male baboons. Anim Behav 51:1269-1277

Alberts SC, Sapolsky RM, Altmann J (1992) Behavioral, endocrine, and immunological correlates of immigration by an aggressive male into a natural primate group. Horm Behav 26:167-178

Albers PCH, de Vries H (2001) Elo-rating as a tool in the sequential estimation of dominance strengths. Anim Behav 61:489-495

Altmann J (1974) Observational study of behaviour: sampling methods. Behaviour 49:227267

Altmann J (1980) Baboon mothers and infants. Harvard University Press, Cambridge, MA

Altmann J, Alberts SC (2003) Variability in reproductive success viewed from a life-history perspective in baboons. Am J Hum Biol 15:401-409

Altmann SA (1973) The pregnancy sign in savannah baboons. J Zoo Anim Med 4:8-12

Archie EA, Tung J, Clark M, Altmann J, Alberts SC (2014) Social affiliation matters : both same-sex and opposite-sex relationships predict survival in wild female baboons. Proc $\mathrm{R}$ Soc B 281:20141261 
Aureli F, Yates K (2009) Distress prevention by grooming others in crested black macaques. Biol Lett 6:27-29

Bales KB (1980) Cumulative scaling of paternalistic behavior in primates. Am Nat 454-461

Bates D, Maechler M, Bolker B, Walker S (2014) lme4: linear mixed-effects models using Eigen and S4. R package version 1.1-7, https://cran.rproject.org/web/packages/lme4/ index.html

Beehner JC, Bergman TJ, Cheney DL, Seyfarth RM, Whitten PL (2005) The effect of new alpha males on female stress in free-ranging baboons. Anim Behav 69:1211-1221

Bergman TJ, Beehner JC, Cheney DL, Seyfarth RM (2003) Hierarchical classification by rank and kinship in baboons. Science 302:1234-1236

Buchan JC, Alberts SC, Silk JB, Altmann J (2003) True paternal care in a multi-male primate society. Nature 425:179-181

Bulger JB (1993) Dominance rank and access to estrous females in male savanna baboons. Behaviour 127:67-103

Cacioppo JT, Hawkley LC (2003) Social isolation and health, with an emphasis on underlying mechanisms. Perspect Biol Med 46:S39-S52

Cameron EZ, Setsaas TH, Linklater WL (2009) Social bonds between unrelated females increase reproductive success in feral horses. Proc Natl Acad Sci USA 106:13850-13853

Charpentier MJE, Van Horn RC, Altmann J, Alberts SC (2008) Paternal effects on offspring fitness in a multimale primate society. Proc Natl Acad Sci USA 105:1988-1992

Cheney DL, Silk JB, Seyfarth RM (2012) Evidence for intrasexual selection in wild female baboons. Anim Behav 84:21-27

Colmenares F, Gomendio M (1988) Changes in female reproductive condition following male take-overs in a colony of hamadryas and hybrid baboons. Folia Primatol 50:157-174

Cowlishaw G (1997) Refuge use and predation risk in a desert baboon population. Anim Behav 54:241-53

Cushing BS, Carter CS (2000) Peripheral pulses of oxytocin increase partner preferences in female, but not male, prairie voles. Horm Behav 37:49-56

Daspre A, Heistermann M, Hodges JK, Lee PC, Rosetta L (2009) Signals of female reproductive quality and fertility in colony-living baboons (Papio h. anubis) in relation to ensuring paternal investment. Am J Primatol 71:529-538

DeVries AC, Glasper ER, Detillion CE (2003) Social modulation of stress responses. Physiol Behav 79:399-407

Ellis JJ, Maclarnon AM, Heistermann M, Semple S (2011) The social correlates of selfdirected behaviour and faecal glucocorticoid levels among adult male olive baboons (Papio hamadryas anubis) in Gashaka-Gumti National Park, Nigeria. Afr Zool 46:302308

Engh AL, Beehner JC, Bergman TJ, Whitten PL, Hoffmeier RR, Seyfarth RM, Cheney DL (2006) Female hierarchy instability, male immigration and infanticide increase glucocorticoid levels in female chacma baboons. Anim Behav 71:1227-1237

Feldman R, Zagoory-Sharon O, Weisman O, Schneiderman I, Gordon I, Maoz R, Shalev I, 
Ebstein RP (2012) Sensitive parenting is associated with plasma oxytocin and polymorphisms in the OXTR and CD38 Genes. Biol Psychiat 72:175-181

Frere CH, Krutzen M, Mann J, Connor RC, Bejder L, Sherwin WB (2010) Social and genetic interactions drive fitness variation in a free-living dolphin population. Proc Natl Acad Sci USA 107:19949- 19954

Gilbert C, Gillman J (1952) Pregnancy in the baboon (Papio ursinus). S Afr J Med Sci 16:115-124.

Grewen KM, Girdler SS, Amico J, Light KC (2005) Effects of partner support on resting oxytocin, cortisol, norepinephrine, and blood pressure before and after warm partner contact. Psychosom Med 67:531-538

Handley LJL, Perrin N (2007) Advances in our understanding of mammalian sex-biased dispersal. Mol Ecol 16:1559-1578

Higham JP, Heistermann M, Ross C, Semple S, MacLarnon A (2008) The timing of ovulation with respect to sexual swelling detumescence in wild olive baboons. Primates 49:295299

Hinde RA, Atkinson S (1970) Assessing the role of social partners in maintaining mutual proximity, as exemplified by mother-infant relations in rhesus monkeys. Anim Behav 18:169-176

Hinde RA, Proctor LP (1977) Changes in the relationships of captive rhesus monkeys on giving birth. Behaviour 61:304-321

Holt-Lunstad J, Smith TB, Bradley Layton J (2010) Social relationships and mortality risk: a meta-analytic review. PLoS Med 7:859

Huchard E, Alvergne A, Fejan D, Knapp LA, Cowlishaw G, Raymond M (2010) More than friends? Behavioural and genetic aspects of heterosexual associations in wild chacma baboons. Behav Ecol Sociobiol 64:769-781

Huchard E, Charpentier MJ, Marshall H, King AJ, Knapp LA., Cowlishaw G (2013) Paternal effects on access to resources in a promiscuous primate society. Behav Ecol 24:229-236

Huchard E, Courtiol A, Benavides JA, Knapp LA, Raymond M, Cowlishaw G (2009) Can fertility signals lead to quality signals? Insights from the evolution of primate sexual swellings. Proc R Soc Lond B 276:1889-1897

Huchard E, Cowlishaw G (2011) Female-female aggression around mating: an extra cost of sociality in a multimale primate society. Behav Ecol 22:1003-1011

Kaplan BS, O'Riain MJ, van Eeden R, King AJ (2011) A low-cost manipulation of food resources reduces spatial overlap between baboons (Papio ursinus) and humans in conflict. Int J Primatol 32:1397-1412

Kerhoas D, Perwitasari-Farajallah D, Agil M, Widdig A, Engelhardt A (2014) Social and ecological factors influencing offspring survival in wild macaques. Behav Ecol 25:11641172

King AJ, Douglas CMS, Huchard E, Isaac NJB, Cowlishaw G (2008) Dominance and affiliation mediate despotism in a social primate. Curr Biol 18:1833-1838

Kulik L, Muniz L, Mundry R, Widdig A (2012) Patterns of interventions and the effect of coalitions and sociality on male fitness. Mol Ecol 21:699-714 
Lemasson A, Palombit RA, Jubin R (2008) Friendships between males and lactating females in a free-ranging group of olive baboons (Papio hamadryas anubis): evidence from playback experiments. Behav Ecol Sociobiol 62:1027-1035

Machanda ZP, Gilby IC, Wrangham RW (2013) Male-female association patterns among free-ranging chimpanzees (Pan troglodytes schweinfurthii). Int J Primatol 34:917-938

Manson JH (1994) Mating patterns, mate choice, and birth season heterosexual relationships in free-ranging rhesus macaques. Primates 35:417-433

Massen JJM, Overduin-de Vries AM, de Vos-Rouweler AJM, Spruijt BM, Doxiadis GGM, Sterck EHM (2012) Male mating tactics in captive rhesus macaques (Macaca mulatta): the influence of dominance, markets, and relationship quality. Int J Primatol 33:73-92

Ménard N, von Segesser F, Scheffrahn W, Pastorini J, Vallet D, Gaci B, Martin RD, GautierHion A (2001) Is male-infant caretaking related to paternity and/or mating activities in wild Barbary macaques (Macaca sylvanus). CR Acad Sci III-Vie 324:601-610

Moscovice LR, Di Fiore A, Crockford C, Kitchen DM, Wittig R, Seyfarth RM, Cheney DL (2010) Hedging their bets? Male and female chacma baboons form friendships based on likelihood of paternity. Anim Behav 79:1007-1015

Moscovice LR, Heesen M, Di Fiore A, Seyfarth RM, Cheney DL (2009) Paternity alone does not predict long-term investment in juveniles by male baboons. Behav Ecol Sociobiol 63:1471-1482

Moscovice LR, Ziegler TE (2012) Peripheral oxytocin in female baboons relates to estrous state and maintenance of sexual consortships. Horm Behav 62:592-597

Mundry R, Nunn CL (2009) Stepwise model fitting and statistical inference: turning noise into signal pollution. Am Nat 173:119-123

Neumann C, Duboscq J, Dubuc C, Ginting A, Irwan AM, Agil M, Widdig A, Engelhardt A (2011) Assessing dominance hierarchies: validation and advantages of progressive evaluation with Elo-rating. Anim Behav 82:911-921

Nguyen N, Van Horn RC, Alberts SC, Altmann J (2009) "Friendships" between new mothers and adult males: adaptive benefits and determinants in wild baboons (Papio cynocephalus). Behav Ecol Sociobiol 63:1331-1344

Ostner J, Vigilant L, Bhagavatula J, Franz M, Schülke O (2013) Stable heterosexual associations in a promiscuous primate. Anim Behav 86:623-631

Palombit RA (1999) Infanticide and the evolution of pair bonds in nonhuman primates. Evol Anthropol 7:117-129

Palombit RA (2000) Infanticide and the evolution of male-female bonds in animals. In: van Schaik CP, Janson CH (eds) Infanticide by males and its implications. Cambridge University Press, Cambridge, pp 239-268

Palombit RA (2003) Male infanticide in wild savanna baboons: adaptive significance and intraspecific variation. In: Jones CB (ed) Sexual selection and reproductive competition in primates: new perspectives and directions. American Society of Primatologists, pp $367-412$

Palombit RA (2012) Infanticide: male strategies and female counterstrategies. In: Mitani JC, Call J, Kappeler PM, Palombit RA, Silk JA (eds) The evolution of primate societies. University of Chicago Press, Chicago, pp 432-468 
Palombit RA, Cheney DL, Fisher J, Johnson S, Rendall D, Seyfarth RM, Silk JB (2000) Male infanticide and defense of infants in chacma baboons. In: van Schaik C, Janson C (eds) Infanticide by males and its implications, Cambridge. Cambridge, pp 123-152

Palombit RA, Cheney DL, Seyfarth RM (2001) Female-female competition for male "friends" in wild chacma baboons, Papio cynocephalus ursinus. Anim Behav 61:1159-1171

Palombit RA, Seyfarth RM, Cheney DL (1997) The adaptive value of "friendships" to female baboons: experimental and observational evidence. Anim Behav 54:599-614

Paul A, Kuester J, Arnemann J (1996) The sociobiology of male-infant interactions in Barbary macaques, Macaca sylvanus. Anim Behav 51:155-170

Pereira ME (1983) Abortion following the immigration of an adult male baboon (Papio cynocephalus). Am J Primatol 4:93-98

Pinheiro JC, Bates DM (2000) Mixed-effects models in S and S-plus. Springer, New York

R Core Development Team (2015) R: A language and environment for statistical computing. Vienna, Austria, http://www.r-project.org/

Roberts EK, Lu A, Bergman TJ, Beehner JC (2012) A Bruce effect in wild geladas. Science 335:1222-1225

Rosal MC, King J, Ma Y, Reed GW (2004) Stress, social support, and cortisol: inverse associations? Behav Med 30:11-21

Seyfarth RM (1976) Social relationships among adult female baboons. Anim Behav 24:917938

Seyfarth RM (1978) Social relationships among adult male and female baboons. II. Behaviour throughout the female reproductive cycle. Behaviour 64:227-247

Silk JB (2007a) The adaptive value of sociality in mammalian groups. Philos T Roy Soc B 362:539-559

Silk JB (2007b) Social components of fitness in primate groups. Science 317:1347-1351

Silk JB, Alberts SC, Altmann J (2003) Social bonds of female baboons enhance infant survival. Science 302:1231-1232

Silk JB, Beehner JC, Bergman TJ, Crockford C, Engh AL, Moscovice LR, Wittig RM, Seyfarth RM, Cheney DL (2009) The benefits of social capital: close social bonds among female baboons enhance offspring survival. Proc R Soc Lond B 276:3099-3104

Silk JB, Beehner JC, Bergman TJ, Crockford C, Engh AL, Moscovice LR, Wittig RM, Seyfarth RM, Cheney DL (2010) Strong and consistent social bonds enhance the longevity of female baboons. Curr Biol 20:1359-1361

Smith AS, Ågmo A, Birnie AK, French JA (2010) Manipulation of the oxytocin system alters social behavior and attraction in pair-bonding primates, Callithrix penicillata. Horm Behav 57:255-262

Smuts BB (1985) Sex and friendship in baboons. Aldine, New york

Smuts BB, Gubernick DJ (1992) Male-infant relationships in nonhuman primates: paternal investment or mating effort? In: Hewlett BS (ed) Father-child relations: cultural and biosocial contexts. Adline, New York, pp 1-30

Snowdon CT, Pieper BA, Boe CY, Cronin KA, Kurian A V, Ziegler TE (2010) Variation in 
oxytocin is related to variation in affiliative behavior in monogamous, pairbonded tamarins. Horm Behav 58:614-618

Stanton MA, Mann J (2012) Early social networks predict survival in wild bottlenose dolphins. PLoS ONE 7:e47508

Sterck EHM, Watts DP, van Schaik CP (1997) The evolution of female social relationships in nonhuman primates. Behav Ecol Sociobiol 41:291-309

Uchino BN (2006) Social support and health: a review of physiological processes potentially underlying links to disease outcomes. J Behav Med 29:377-387

van Schaik CP (1989) The ecology of social relationships amongst female primates. In: Standen V, Foley RA (eds) Comparative socioecology: the behavioral ecology of humans and other mammals. Blackwell Scientific, Oxford, GB, pp 195-218

van Schaik CP, Kappeler PM (1997) Infanticide risk and the evolution of male-female association in primates. Proc R Soc Lond B 264:1687-1694

van Schaik CP, Paul A (1996) Male care in primates: does it ever reflect paternity? Evol Anthropol 5:152-156

van Schaik CP, van Noordwijk MA (1989) The special role of male Cebus monkeys in predation avoidance and its effect on group composition. Behav Ecol Sociobiol 24:265276

Weingrill T (2000) Infanticide and the value of male-female relationships in mountain chacma baboons. Behaviour 137:337-359

Weingrill T, Lycett JE, Barrett L, Hill RA, Henzi SP (2003) Male consortship behaviour in chacma baboons: the role of demographic factors and female conceptive probabilities. Behaviour 140:405-427

Whittingham MJ, Stephens PA, Bradbury RB, Freckleton RP (2006) Why do we still use stepwise modelling in ecology and behaviour? J Anim Ecol 75:1182-1189

Widdig A (2007) Paternal kin discrimination: the evidence and likely mechanisms. Biol Rev $82: 319-334$

Williams JR, Insel TR, Harbaugh CR, Carter CS (1994) Oxytocin administered centrally facilitates formation of a partner preference in female prairie voles (Microtus ochrogaster). J Neuroendocrinol 6:247-250

Witt DM, Carter CS, Walton DM (1990) Central and peripheral effects of oxytocin administration in prairie voles (Microtus ochrogaster). Pharmacol Biochem Behav 37:63-69 
Table 1 Results of the permutation tests investigating whether females remain associated with the same male across reproductive states (likely father: most likely father of their offspring, identified as the main consort during the swollen period of the conceptive cycle, friend P: male friend during pregnancy, friend L: male friend during lactation, previous friend: male friend during pregnancy or lactation of the previous interbirth interval). The observed proportion of females associated with the same male is calculated as the number of females associated with the same male across both reproductive states divided by the total number of females

\begin{tabular}{|c|c|c|c|c|c|c|c|}
\hline Transition & $\begin{array}{c}\text { Observed } \\
\text { proportion of } \\
\text { females } \\
\text { associated } \\
\text { with the same } \\
\text { male } \\
\end{array}$ & $\begin{array}{l}\text { Proportion of females } \\
\text { associated with the } \\
\text { same male between } \\
\text { randomized matrices } \\
{[95 \% \mathrm{CI}]}\end{array}$ & P-value & $\begin{array}{c}\text { Number } \\
\text { of } \\
\text { females }\end{array}$ & $\begin{array}{l}\text { Number of females } \\
\text { associated with the } \\
\text { same male across } \\
\text { both reproductive } \\
\text { states }\end{array}$ & $\begin{array}{c}\text { Number of } \\
\text { females } \\
\text { switching males } \\
\text { across both } \\
\text { reproductive } \\
\text { states } \\
\end{array}$ & $\begin{array}{l}\text { Number of } \\
\text { females } \\
\text { without } \\
\text { associate in } \\
\text { one state }\end{array}$ \\
\hline Likely father - friend $\mathrm{P}$ & 0.840 & $0.118[0.000 ; 0.240]$ & $<0.001$ & 25 & 21 & 3 & 1 \\
\hline Friend $\mathrm{P}$ - friend $\mathrm{L}$ & 0.526 & $0.114[0.000 ; 0.263]$ & $<0.001$ & 19 & 10 & 3 & 6 \\
\hline Previous friend - likely father & 0.100 & $0.093[0.000 ; 0.300]$ & 0.579 & 10 & 1 & 9 & 0 \\
\hline
\end{tabular}


949

Table 2 Results of the mixed models analysing the frequency of association (a) between a female and her consort partner and (b) between a female and her male friend, during the conceptive cycle (SWc), pregnancy (P), early lactation (L1), late lactation (L2) and the first postpartum cycle (SW1). The parameters are based on observations including 52 females in a particular reproductive state (26 individual females), 11 males and 5085 and 2407 proximity scans for the first model and on 71 females in a particular reproductive state (33 individual females), 18 males and 7584 proximity scans for the second models. Parameter estimates were computed using mixed models controlling for the non-independence of scans within focal observations, and for the repeated appearance of females and males (fitted as random factors). se: standard error. Significant effects (for which confidence interval does not cross zero) are indicated in bold

\begin{tabular}{|c|c|c|c|c|c|c|c|}
\hline $\begin{array}{l}\text { Response } \\
\text { variable }\end{array}$ & Fixed factors & Levels & Estimate \pm se & $\begin{array}{c}95 \% \text { confidence } \\
\text { interval }\end{array}$ & LRT & df & P-value \\
\hline \multirow{9}{*}{$\begin{array}{l}\text { (a) Probability } \\
\text { of association } \\
\text { with the most } \\
\text { likely father }\end{array}$} & Reproductive state $^{\mathrm{a}}$ & SWc & $0.812 \pm 0.833$ & {$[-0.820 ; 2.444]$} & \multirow{3}{*}{31.276} & \multirow{3}{*}{3} & \multirow{3}{*}{$<0.001$} \\
\hline & & $\mathrm{P}$ & $-1.572 \pm 0.772$ & {$[-3.086 ;-0.058]$} & & & \\
\hline & & L2 & $-0.121 \pm 1.023$ & {$[-2.126 ; 1.883]$} & & & \\
\hline & Female rank & & $2.801 \pm 0.741$ & {$[1.349 ; 4.253]$} & 12.130 & 1 & $<0.001$ \\
\hline & Male rank & & $2.848 \pm 1.041$ & {$[0.808 ; 4.889]$} & 7.402 & 1 & 0.007 \\
\hline & \multirow[t]{2}{*}{ Parity $^{\mathrm{b}}$} & nulliparous & $-1.916 \pm 0.613$ & {$[-3.118 ;-0.715]$} & \multirow{2}{*}{13.052} & \multirow{2}{*}{2} & \multirow{2}{*}{0.001} \\
\hline & & primiparous & $-2.135 \pm 0.701$ & {$[-3.508 ;-0.762]$} & & & \\
\hline & Troop $^{c}$ & & $0.574 \pm 0.490$ & {$[-0.386 ; 1.534]$} & 1.315 & 1 & 0.251 \\
\hline & Year $^{\mathrm{d}}$ & & $0.685 \pm 0.594$ & {$[-0.479 ; 1.850]$} & 1.270 & 1 & 0.260 \\
\hline \multirow{3}{*}{$\begin{array}{l}\text { (b) Probability } \\
\text { of association } \\
\text { with the male }\end{array}$} & Reproductive state $^{\mathrm{a}}$ & $\bar{P}$ & $-1.380 \pm 0.283$ & {$[-1.934 ;-0.825]$} & \multirow{3}{*}{33.144} & \multirow{3}{*}{3} & \multirow{3}{*}{$<0.001$} \\
\hline & & L2 & $-0.861 \pm 0.379$ & {$[-1.603 ;-0.118]$} & & & \\
\hline & & SW1 & $-2.359 \pm 0.486$ & {$[-3.312 ;-1.407]$} & & & \\
\hline
\end{tabular}


950

\begin{tabular}{|c|c|c|c|c|c|c|c|}
\hline \multirow[t]{5}{*}{ friend } & Female rank & & $1.318 \pm 0.492$ & {$[0.354 ; 2.281]$} & 6.167 & 1 & 0.013 \\
\hline & Male rank & & $-0.961 \pm 0.532$ & {$[-2.003 ; 0.081]$} & 3.275 & 1 & 0.070 \\
\hline & Parity $^{b}$ & $\begin{array}{l}\text { nulliparous } \\
\text { primiparous }\end{array}$ & $\begin{array}{l}-0.042 \pm 0.484 \\
-0.002 \pm 0.302\end{array}$ & $\begin{array}{l}{[-0.990 ; 0.906]} \\
{[-0.595 ; 0.591]}\end{array}$ & 0.005 & 2 & 0.997 \\
\hline & Troop $^{c}$ & & $0.267 \pm 0.465$ & {$[-0.645 ; 1.179]$} & 0.302 & 1 & 0.582 \\
\hline & Year $^{\mathrm{d}}$ & & $1.072 \pm 0.286$ & {$[0.512 ; 1.633]$} & 13.669 & 1 & $<0.001$ \\
\hline
\end{tabular}

${ }^{a}$ Reference category: L1 (six first months of lactation)

${ }^{\mathrm{b}}$ Reference category: multiparous

${ }^{\mathrm{c}}$ Reference category: J group

${ }^{\mathrm{d}}$ Reference category: 2013 
Fig. 1 Distribution of grooming (white bars) and spatial proximity (grey bars) indices (a) between each female and five male residents in her group that ranked from the highest to the fifth highest score, and (b) for friend dyads $(\mathrm{N}=77$ for grooming index, $\mathrm{N}=55$ for proximity index) versus non-friend dyads ( $\mathrm{N}=902$ for grooming index, $\mathrm{N}=812$ for proximity index). On each box, the black horizontal line represents the median of the distribution, while the bottom and top of the box represent respectively the 25th and 75th quartiles. Whiskers include a maximum of half of the interquartile range. Open dots represent outliers. Note that the boxes representing the grooming index distribution for the fifth male and for non-friend dyads is not visible because the median, the $25^{\text {th }}$ and $75^{\text {th }}$ quartiles are equal to zero

(a)

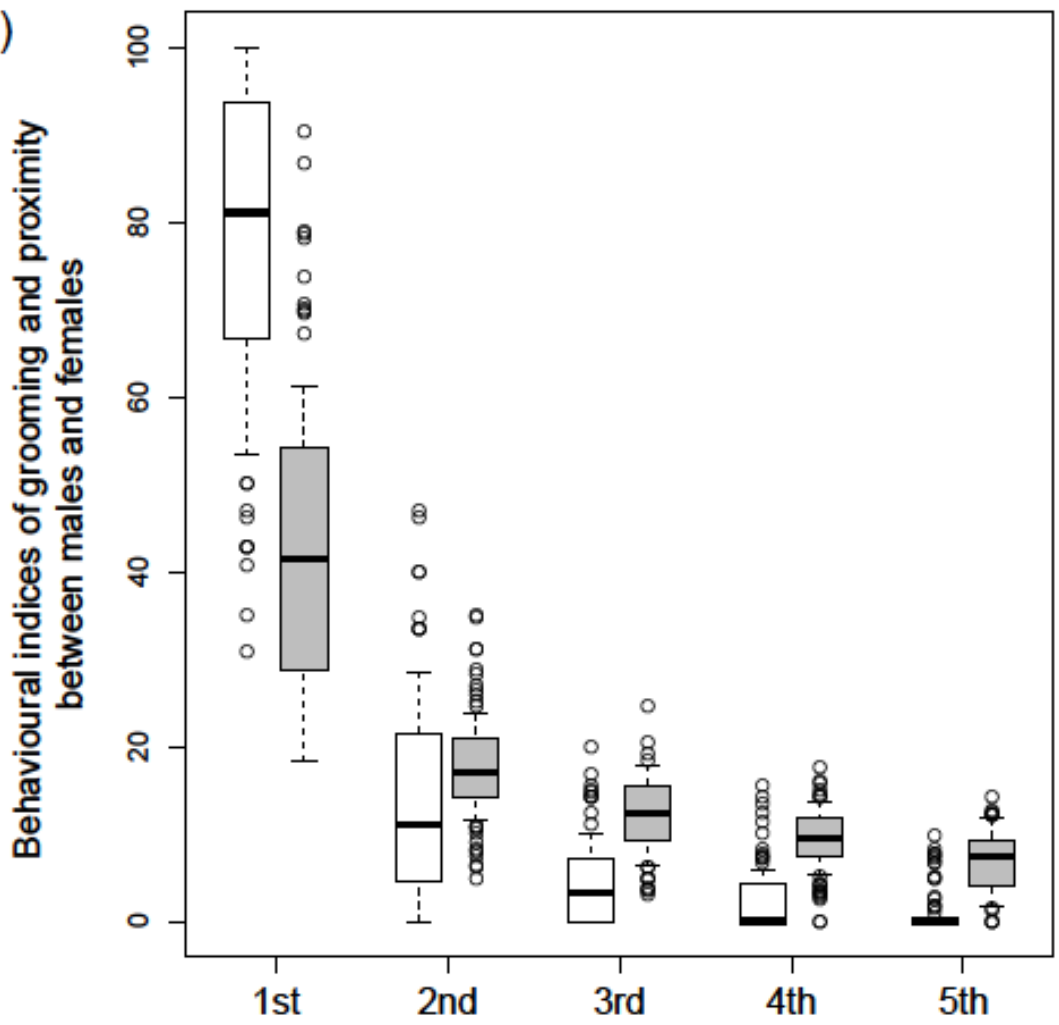

(b)

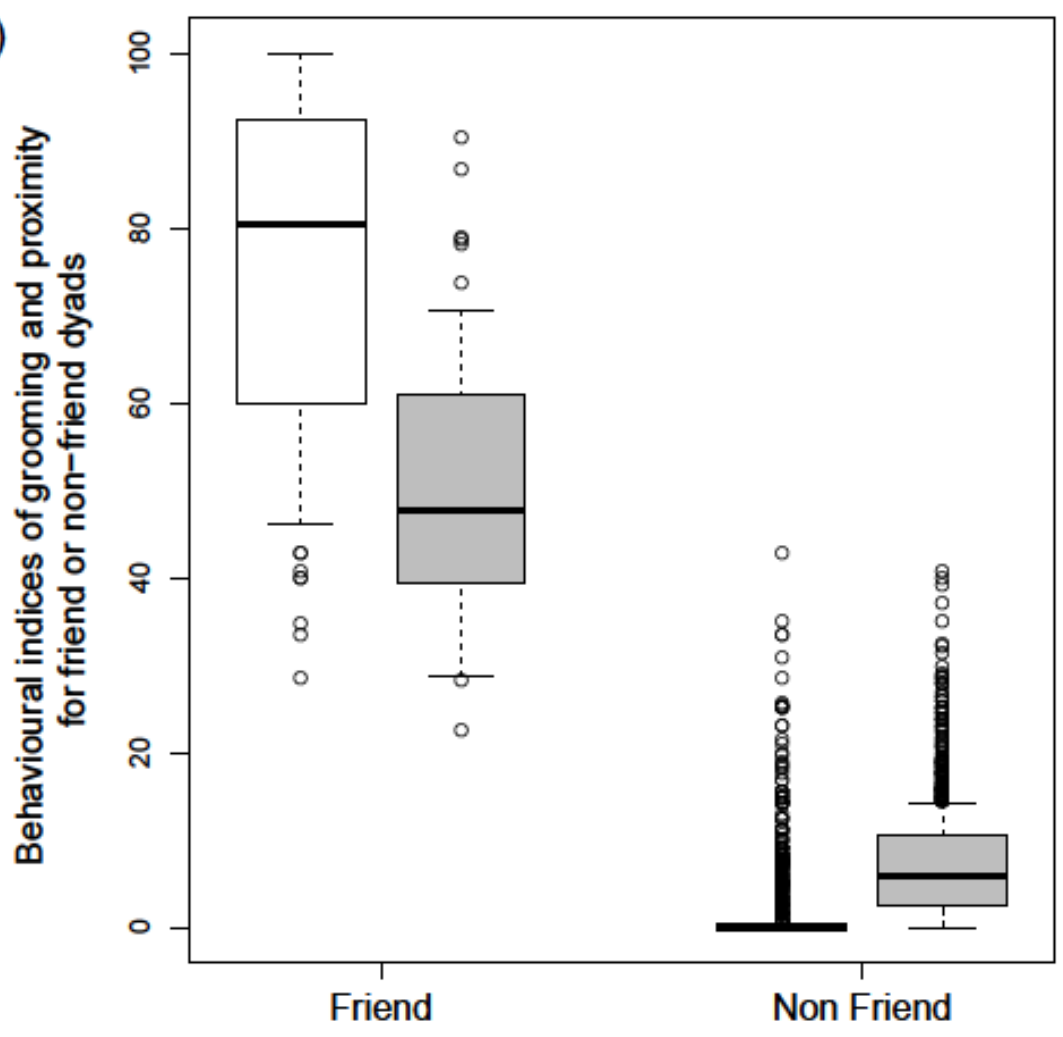


Fig. 2 Responsibility for the maintenance of close spatial proximity (within $1 \mathrm{~m}$ ) between females and their male associates. The male associate is the male consort during the swollen period of the conceptive cycle (SWC) and the male friend during pregnancy (P), early lactation (L1) and late lactation (L2). Responsibility is measured by Hinde's index: positive (vs negative) values indicate that the female (vs male) is primarily responsible for maintaining proximity. The number of females in each reproductive state is indicated above the boxplot. On each box, the black horizontal line represents the median of the distribution, while bottom and top of the box represent respectively the 25th and 75th quartiles. Whiskers include a maximum of half of the interquartile range. Open dots represent outliers

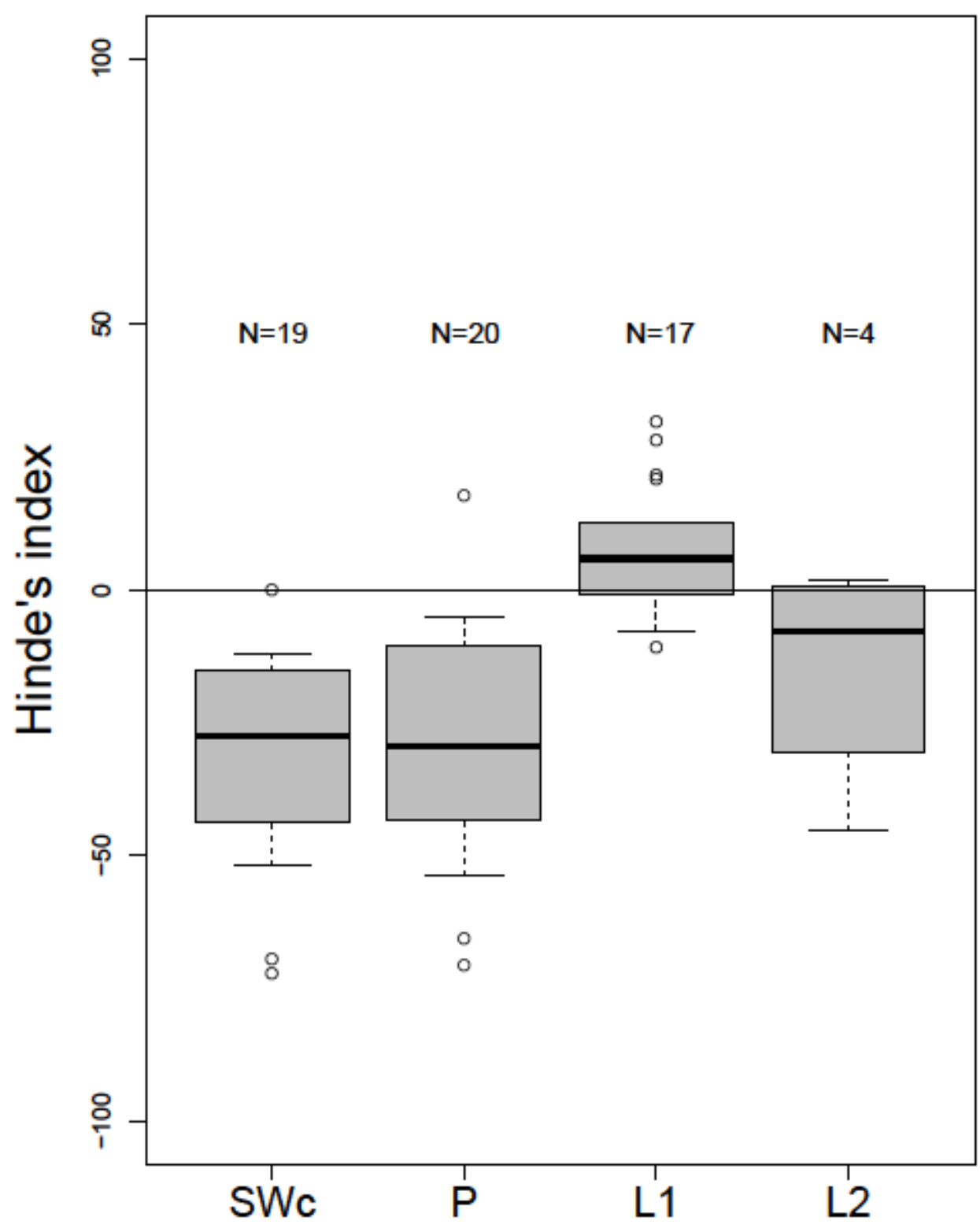

972 
Fig. 3 Distribution of the proportion of proximity scans for which (a) the likely father and (b) the male friend is the nearest neighbour (calculated as the number of scans with the male partner as the nearest neighbour divided by the total number of scans available for the female), according to female reproductive state: cycling swollen during the conceptive cycle (SWc), pregnant (P), early lactation (L1), late lactation (L2) and first postpartum cycle (SW1). On each box, the black horizontal line represents the median of the distribution, while bottom and top of the box represent respectively the 25th and 75th quartiles. Whiskers include a maximum of half of the interquartile range. Open dots represent outliers. The significance of the comparisons between reproductive states is evaluated by changing contrasts in the GLMM. Significant comparisons are denoted by "*"

(a)

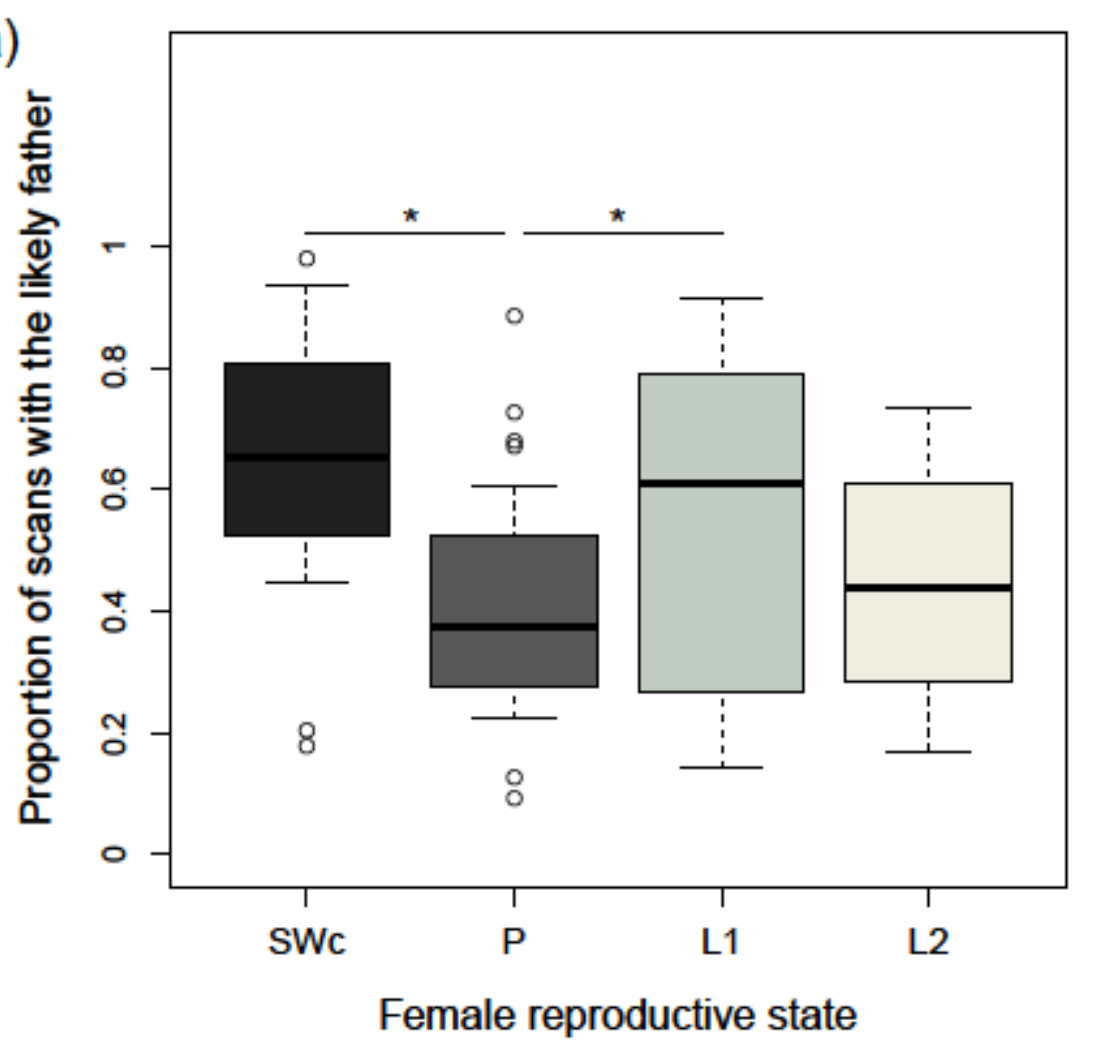

(b)

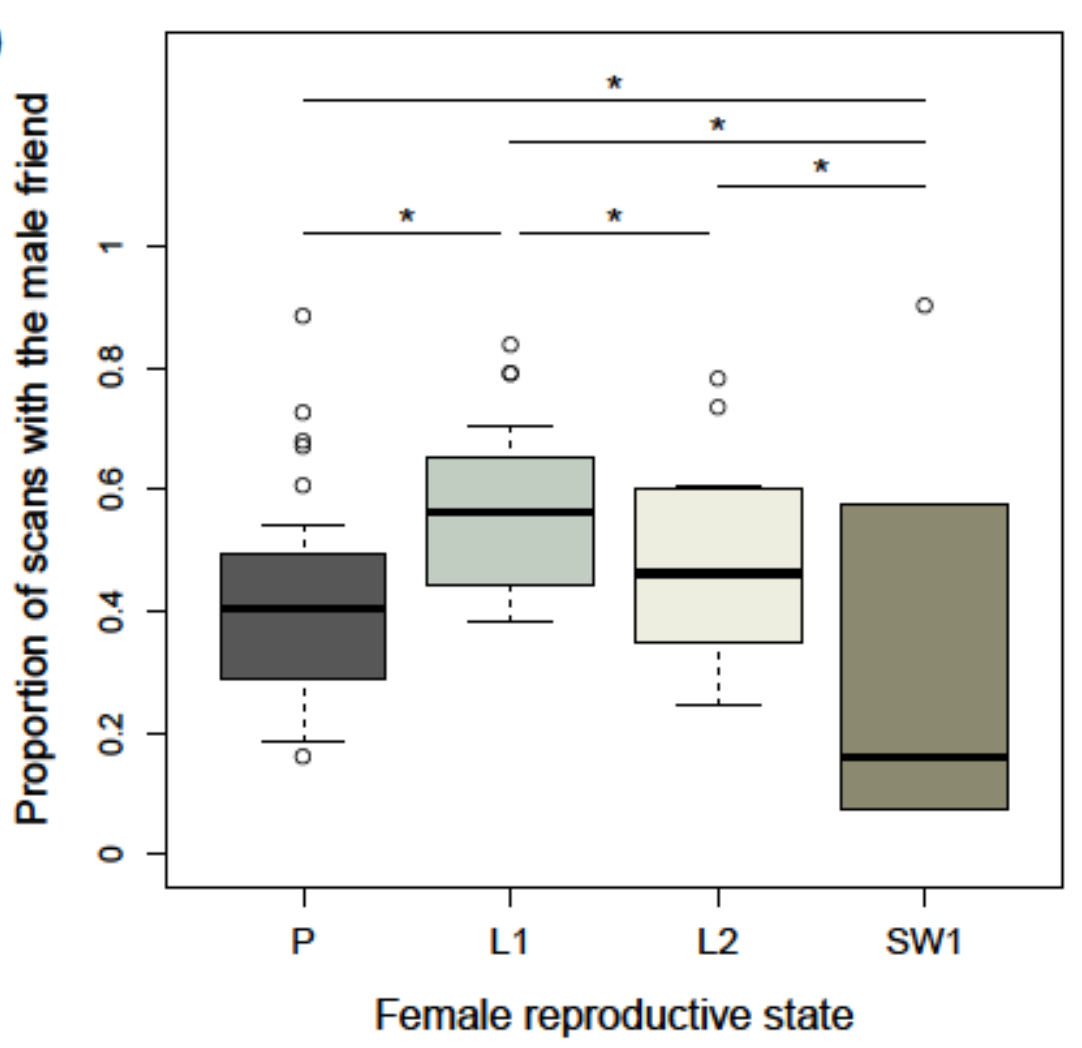




\section{Supplementary Text}

\section{Identification of male friend}

We identified the male friend of each female observed in pregnancy, early lactation and late lactation using dyadic indices of spatial proximity and grooming between each female and all males in the group - see main text for the description of these indices. For each behavioural index, we ranked males from the highest to the lowest score, then calculated the ratio of the highest index divided by the second highest index and the ratio of the second highest index divided by the third highest index. If the first ratio was higher than two (i.e. the male with the highest index has twice as many interactions with the female than the second male), we assigned only one preferred male - the one with the highest score - to the female. If the second ratio was also higher than two, we assigned two preferred males - the ones with first and second highest indices - to the female. Otherwise, we considered that the female had no preferred male for this reproductive state. Thus, females could have one, two or no preferred male(s) if no male had a highly differentiated score compared to the others. When the first highest male had a score of 100 and the second highest male had a score of 0 , the ratio was infinite (100/0). In those cases, the first highest male was assigned as male friend. Similarly, if the ratio between the first and second highest ranking males was inferior to 2 and the ratio between the second and third highest ranking male was infinite, the two first males were assigned as male friends. Females in a given reproductive state were included in the analysis if they had at least 5 grooming bouts recorded with adult males (for the grooming index) and only if they had been the subject of at least 4 focal observations (representing a minimum of 28 informative scans) (see Table S1 for sample size of each index).

Then, we compared the preferred male(s) assigned by each behavioural index and considered as "male friend" the male(s) that was preferred according to both grooming and 
proximity indices. There were more preferred males assigned by the grooming indices than by the proximity indices, because grooming relationships are more differentiated. When a male was assigned as preferred by one index but not by the other ( $\mathrm{N}=23$ out of 81 cases), we checked whether he was also ranking first or second with the other index. In such cases ( $\mathrm{N}=17$ out of 23$)$, we assigned this male as male friend. Otherwise, we did not assign any male friend ( $\mathrm{N}=6$ out of 23). Both indices were very congruent: except for cases where one index did not assign a preferred male while the other did, females had one (and only one) preferred male in common using grooming and proximity indices in 41 out of 42 cases. In the one case when grooming and proximity indices assigned different preferred males $(\mathrm{N}=1$ out of 81), we considered that the female had no male friend. In a few cases, sample sizes were insufficient to calculate indices using both grooming and proximity ( $\mathrm{N}=6$ cases for proximity, where less than four focal follows were available for a female in a given reproductive state and $\mathrm{N}=8$ cases for grooming, where less than five grooming bouts were available for a female in a given reproductive state). We assigned as male friend the male that was assigned as preferred according to the index available. There was no single case where the two same males were assigned by both indices, thus all females had only one male friend. After taking the consensus between both indices, we defined one male friend for $83 \%$ of females $(\mathrm{N}=67$ out of 81 ), namely $83 \%$ of pregnant females, $95 \%$ of females in early lactation and $68 \%$ for females in late lactation had one male friend. 


\section{$\underline{\text { Supplementary Tables }}$}

Table S1 Sample size available to calculate the behavioural indices of heterosexual associations: grooming allocation and spatial proximity allocation (P: pregnant, L1: six first months of lactation, L2: rest of lactation)

\begin{tabular}{lccc}
\hline Measure & $\begin{array}{c}\text { Reproductive } \\
\text { State }\end{array}$ & $\begin{array}{c}\text { Number of } \\
\text { females* }\end{array}$ & $\begin{array}{c}\text { Sample size per female } \\
\text { (mean } \pm \text { sd ; [min-max]) }\end{array}$ \\
\hline Grooming bouts & $\mathrm{P}$ & 35 & $35.2 \pm 33.0 ;[6-142]$ \\
(N=73 females) & L1 & 20 & $43.9 \pm 48.8 ;[6-188]$ \\
& L2 & 18 & $16.1 \pm 9.8 ;[5-38]$ \\
\hline Proximity scans & $\mathrm{P}$ & 37 & $114.6 \pm 44.0 ;[37-198]$ \\
(N=75 females) & L1 & 20 & $115.3 \pm 39.4 ;[43-182]$ \\
& L2 & 18 & $80.7 \pm 30.2 ;[28-151]$ \\
\hline
\end{tabular}

* Several females were observed in different reproductive states (pregnant, early lactation, late lactation) or in different interbirth intervals. They are considered as different statistical units because friendships were established for each reproductive state and interbirth interval. 
Table S2 Sample size and results of the process of friendship assignment for each female in each reproductive state (P: pregnant, L1: six first months of lactation, L2: rest of lactation)

\begin{tabular}{lccc}
\hline Measure & $\begin{array}{c}\text { Reproductive } \\
\text { State }\end{array}$ & $\begin{array}{c}\text { Number of } \\
\text { females with one } \\
\text { or two preferred } \\
\text { male(s) }\end{array}$ & $\begin{array}{c}\text { Number of females } \\
\text { with no preferred } \\
\text { male identified }\end{array}$ \\
\hline Grooming & P & 33 & 2 \\
(N=73 females) & L1 & 20 & 0 \\
& L2 & 17 & 1 \\
\hline Proximity & P & 18 & 19 \\
(N=75 females) & L1 & 17 & 3 \\
& L2 & 11 & 7 \\
\hline Consensus & P & 33 & 7 \\
(N=81 females) & L1 & 21 & 1 \\
& L2 & 13 & 6 \\
\hline
\end{tabular}




\section{$\underline{\text { Supplementary Figures }}$}

Fig. S1 Variation in the Elo-rating dominance rank of males during the study period in J group in 2013. The gap is due to a 15 days interruption in data collection

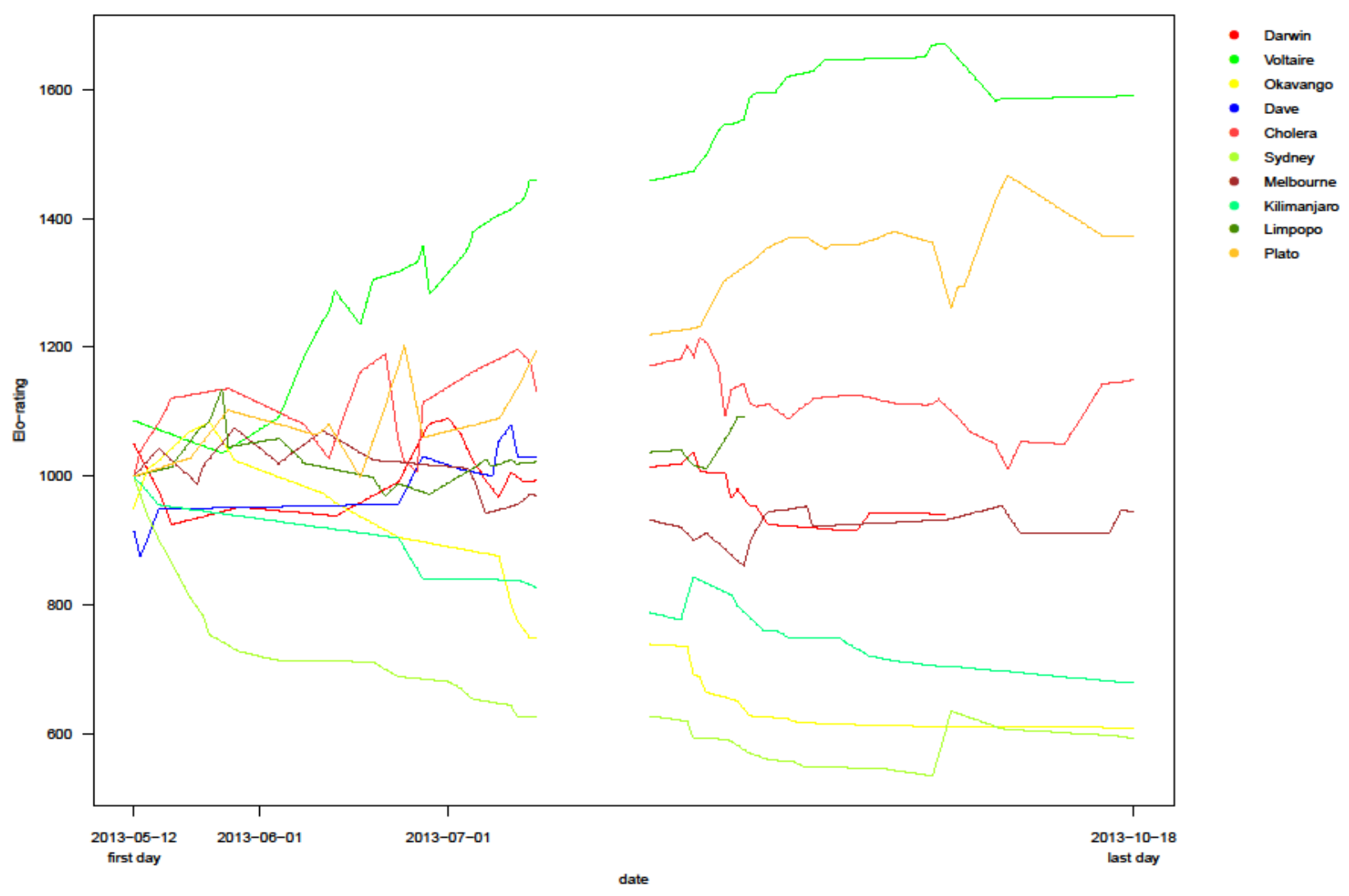


Fig. S2 Variation in the Elo-rating dominance rank of males during the study period in J group in 2014. The gap is due to a 15 days interruption in data collection

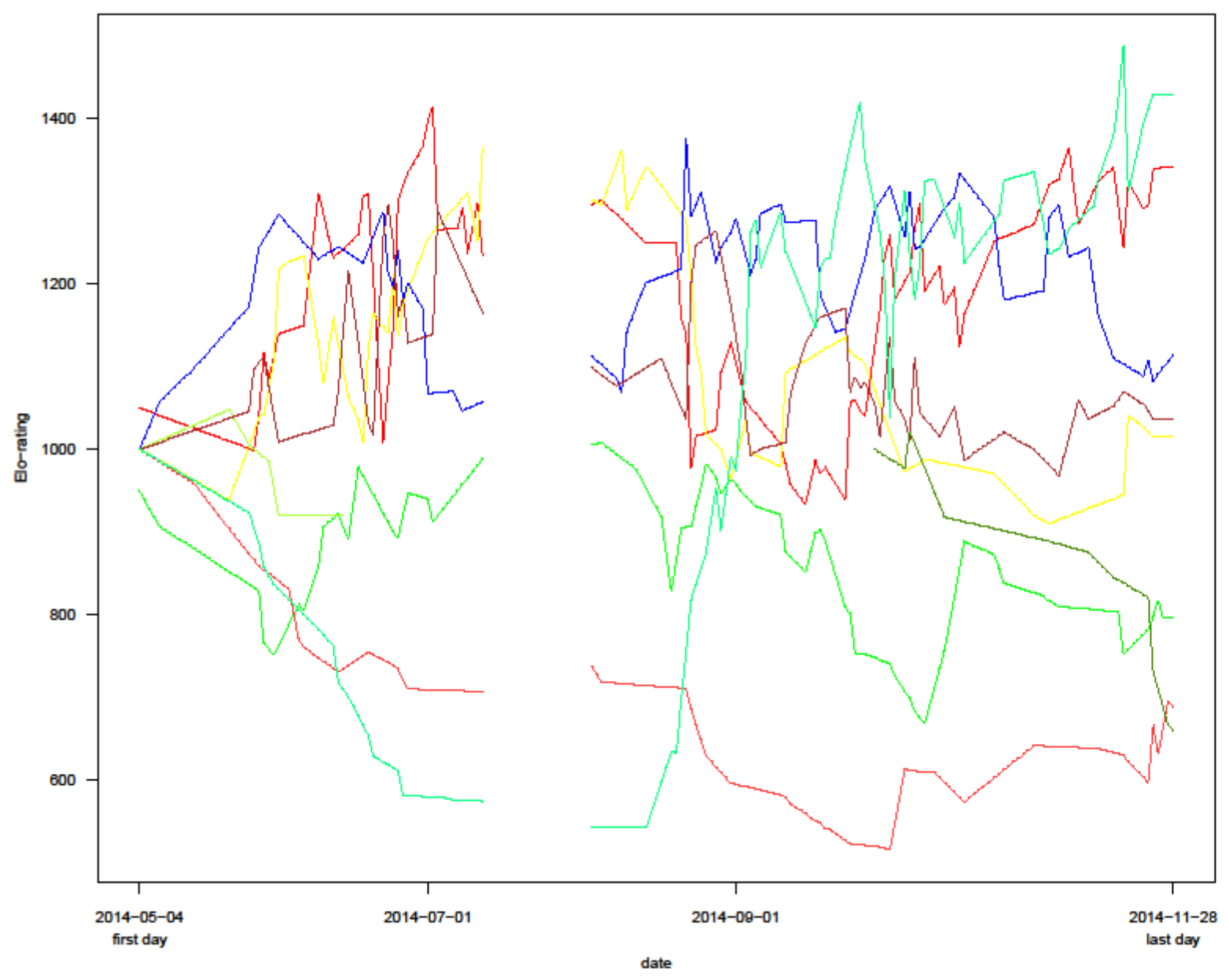

- Edgar

Cholera

- VictorHugo

- Voltaire

- Kilimanjaro

- Wallace

- Marx

- ShyGuy 
Fig. S3 Variation in the Elo-rating dominance rank of males during the study period in L group in 2013. The gap is due to a 15 days interruption in data collection

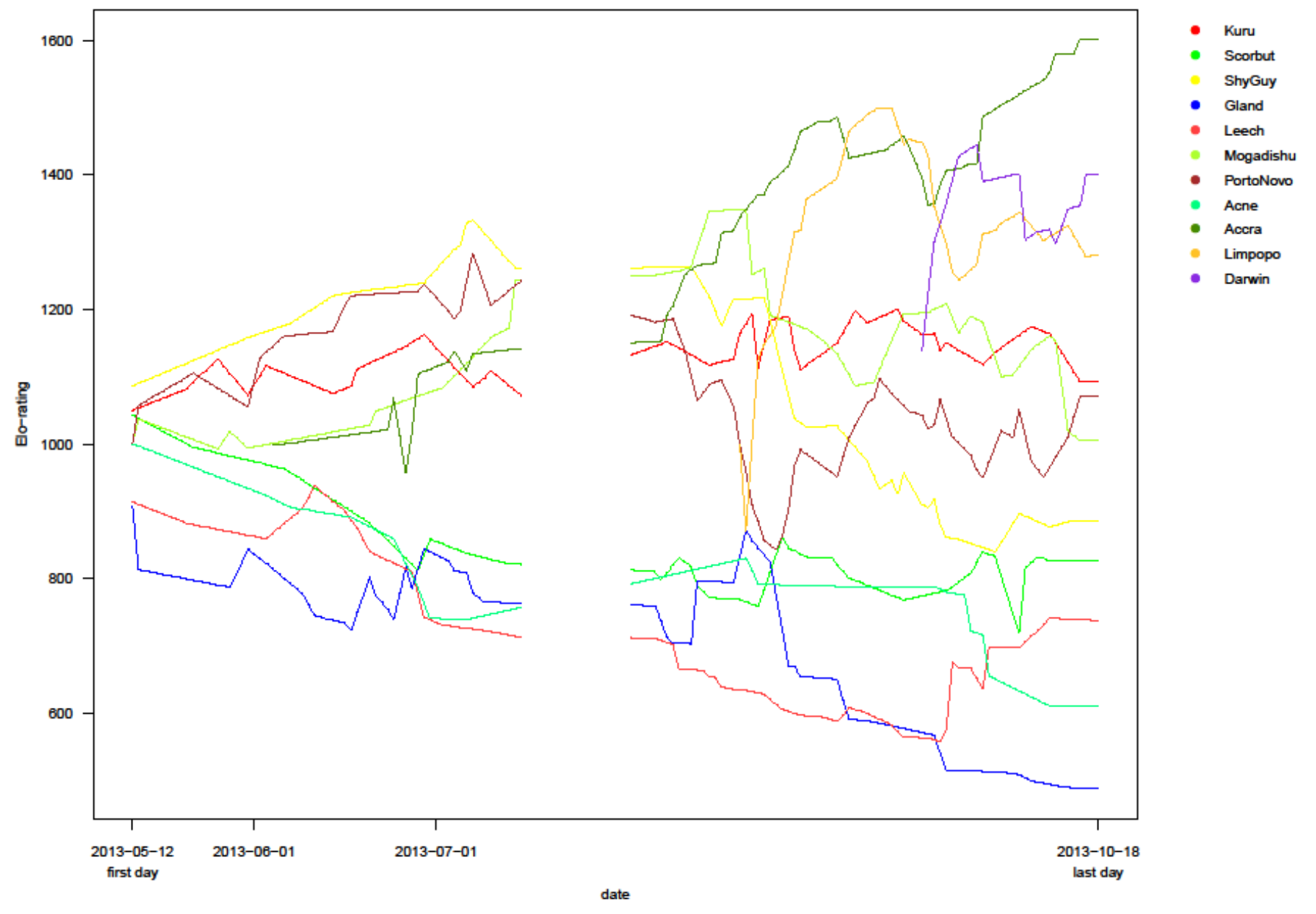


Fig. S4 Variation in the Elo-rating dominance rank of males during the study period in L group in 2014. The gap is due to a 15 days interruption in data collection

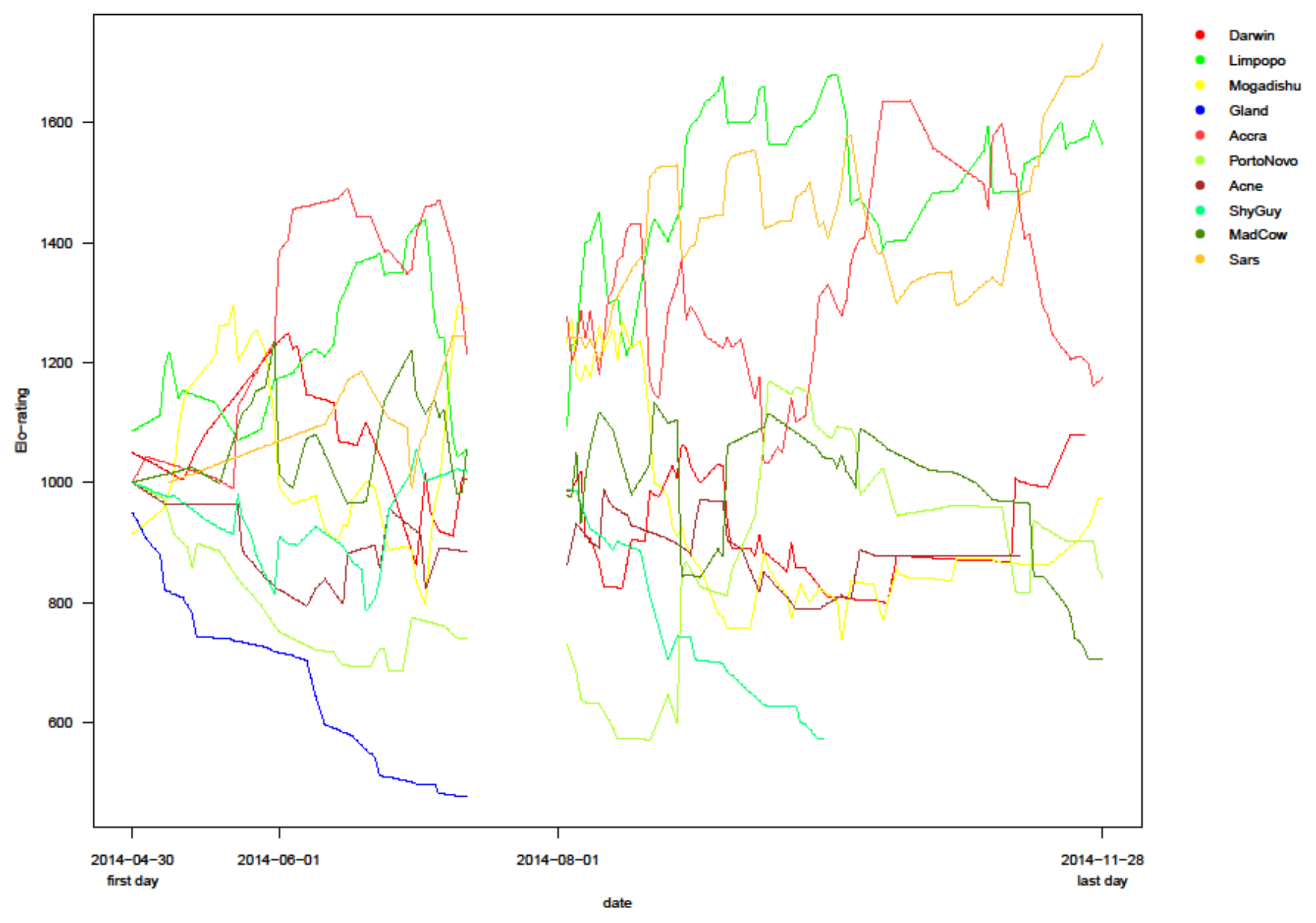


Fig. S5 Responsibility for the maintenance of close spatial proximity (within $1 \mathrm{~m}$ ) (a) between cycling non-swollen females (NSW) and their previous male consort (i.e. their consort during the fertile period of their last oestrus cycle), (b) between early pregnant females $\left(1^{\text {st }}\right.$ month of pregnancy, when it is inconspicuous) and the male consort of their conceptive cycle and (c) between late pregnant females $\left(2^{\text {nd }}-6^{\text {th }}\right.$ month of pregnancy, when it is conspicuous $)$ and the most likely father of their conceptive cycle. Responsibility is measured by Hinde's index: positive (vs negative) values indicate that the female (vs male) is primarily responsible for maintaining proximity. The number of females in each reproductive state is indicated above the boxplot. On each box, the black horizontal line represents the median of the distribution, while bottom and top of the box represent respectively the 25 th and 75 th quartiles. Whiskers include a maximum of half of the interquartile range

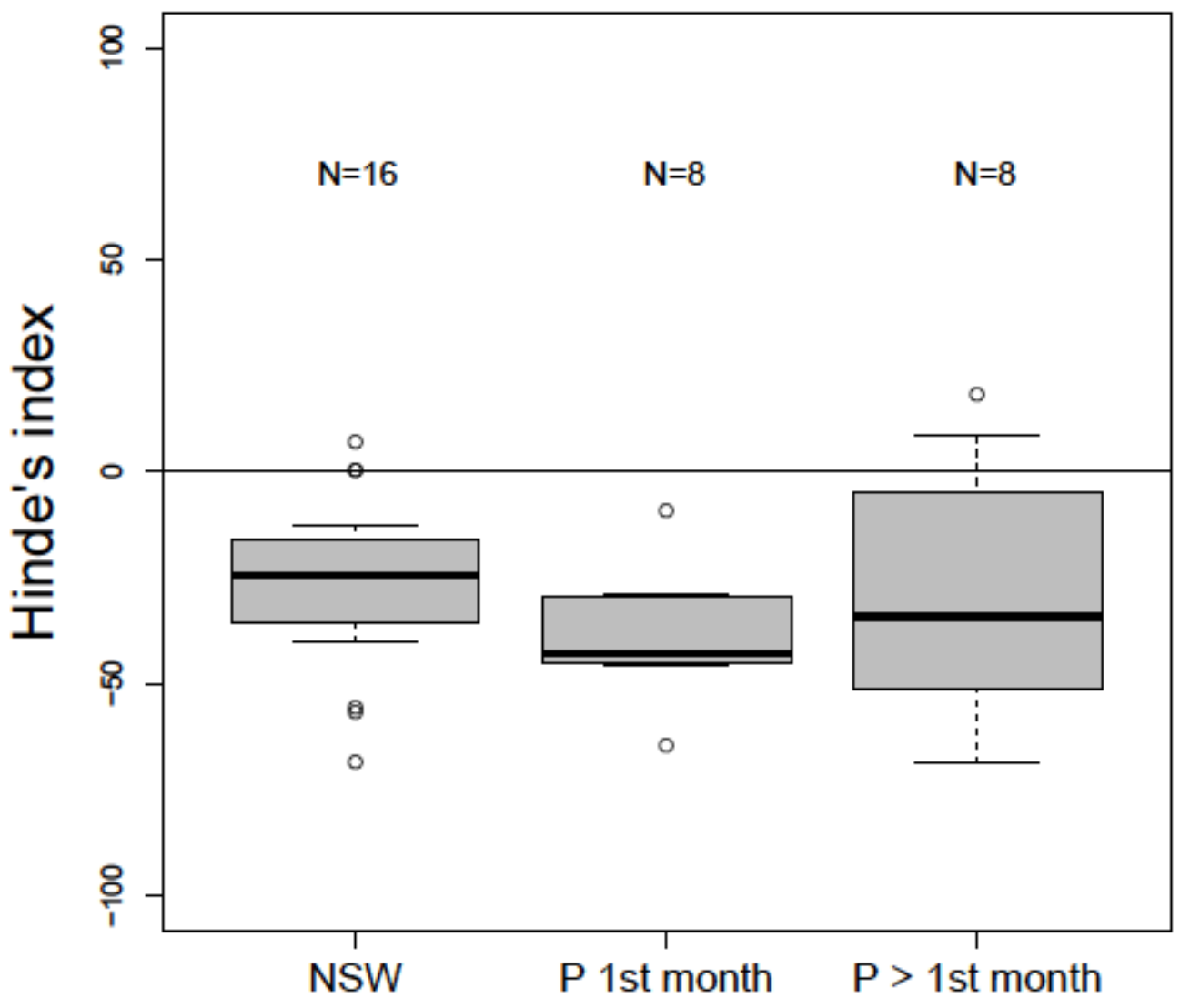

